NASA TECHNICAL NOTE

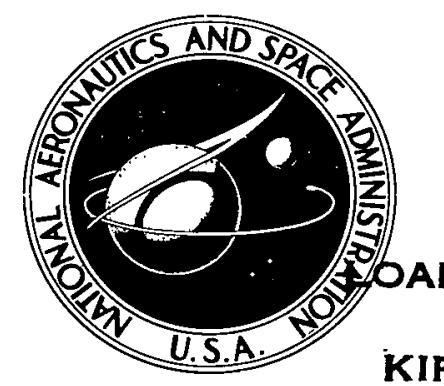

NASA TN D-6645

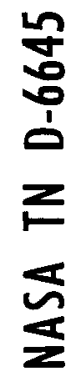
AFWL (D AFWL (D'

SELF CONTAMINATION AND ENVIRONMENT OF AN ORBITING SPACECRAFT

by Jobn J. Scialdone

Goddard Space Flight Center

Greenbelt, Md. 20771

National aERONAUTICS AND SPACE AdMINISTRATION - WASHINGTON, D. C. - MAY 1972 
1. Report No.
NASA TN D-6645

4. Title and Subtitle

Self Contamination and Environment of an Orbiting Spacecraft

7. Author(s)

John J. Scialdone

9. Performing Organization Name and Address

Goddard Space Flight Center

Greenbelt, Maryland 20771

12. Sponsoring Agency Name and Address

National Aeronautics and Space Administration

Washington, D. C. 20546

15. Supplementary Notes

16. Abstract

The flux of molecules emitted by a spacecraft and subsequently reflected to its surface is investigated. The reflection occurs upon collision of the outgassed molecules with ambient molecules. Evaluation of the flux is based on a knowledge of the spacecraft outgassing rate, the spacecraft dimensions, and the orbit parameters. Condensation rates and adsorption layers on critical surfaces are calculated from the knowledge of this flux and the nature and temperature of the gas and the surface. Based on estimated and measured emission rates, calculation of the above parameters is performed for a number of spacecraft.

The relationships and graphs developed allow an estimate of several important parameters for an orbiting spacecraft to be made. The pressures and densities at various distances from the spacecraft, as produced by the surrounding ambient molecules and by the spacecraft's own outgassing, are presented. The pressure and density produced by the outgassing can be obtained as a function of time if the behavior of the outgassing with time is known. The number of desorbed molecules ionized by impact with ambient charged particles and the effect of the spacecraft's electric field on polarized desorbed molecules are considered.

17. Key Words Suggested by Author

Self Contamination

Outgassing

Adsorption

Condensation

19. Security Classif. (of this report)

Unclassified
18. Distribution Stotement

Unclassified-Unlimited

20. Security Classif. (of this page)

Unlimited

\begin{tabular}{|c|c|} 
21. No. of Pages & 22. Price \\
32 & $\$ 3.00$ \\
\hline
\end{tabular}

"For sale by the Netional Technical Information Service, Springfield, Virginia 22151 



\section{CONTENTS}

Abstract . . . . . . . . . . . . . . . . . . . . . . . . . . . . . .

INTRODUCTION . . . . . . . . . . . . . . . . . . . . . . . . . . . . . . 1

CONTAMINATION SOURCES-OUTGASSING . . . . . . . . . . . . . . . . . . . 2

CHARACTERISTICS OF THE GAS AROUND AN ORBITING SPACECRAFT ．．．． . . 4

Desorbed Molecules . . . . . . . . . . . . . . . . . . . . . . . . . . . . 5

Reflected Particles . . . . . . . . . . . . . . . . . . . . . . . . . . 6

DENSITY OF THE MOLECULES LEAVING THE SPACECRAFT ．．．．．．．．． . . 7

DENSITY OF MOLECULES LEAVING AND RETURNING TO THE

SPACECRAFT . . . . . . . . . . . . . . . . . . . . . . . . . . . . . 7

EFFECT OF ELECTRIC POTENTIAL . . . . . . . . . . . . . . . . . . . . . . . . 9

APPLICATION . . . . . . . . . . . . . . . . . . . . . . . . . . . . . . 10

Desorbed Molecules-Condensation Region . . . . . . . . . . . . . . . . . . . 10

Reflected Molecules-Condensation Region . . . . . . . . . . . . . . . . . . 12

Returning Molecules-Condensation Region . . . . . . . . . . . . . . . . . . 12

Light Scattering-Optical Thickness . . . . . . . . . . . . . . . . . . . 16

RAREFACTION REGION . . . . . . . . . . . . . . . . . . . . . . . . . . . 17

CONTAMINATION DUE TO RETURNING FLUX . . . . . . . . . . . . . . . . . 17

Surface Adsorption of the Contaminant . . . . . . . . . . . . . . . . . . . . 17

Contaminant Condensation . . . . . . . . . . . . . . . . . . . . . . . . . 21

NUMERICAL CALCULATIONS . . . . . . . . . . . . . . . . . . . . . . . . 21 


\section{CONTENTS (Continued)}

\section{Page}

CONCLUSION AND SUMMARY . . . . . . . . . . . . . . . . . . . . . . 25

References . . . . . . . . . . . . . . . . . . 26

Uncited References . . . . . . . . . . . . . . . . . . . . . . . . . . . . . . 28

Appendix-Electric Field Considerations . . . . . . . . . . . . . . . . . . . . . . . 29

Ionized Desorbed Molecules _. . . . . . . . . . . . . . . . . . . . . . . . 30

Escape Velocity of Polarized Molecules . . . . . . . . . . . . . . . . . . . . 31 


\title{
SELF-CONTAMINATION AND ENVIRONMENT OF AN ORBITING SPACECRAFT
}

\author{
by \\ John J. Scialdone \\ Goddard Space Flight Center
}

\section{INTRODUCTION}

The environment surrounding an orbiting spacecraft is dictated by the ambient constituents at that altitude and by the particulate and gaseous emission of the spacecraft. The ambient constituents vary according to time (hour, day, sun rotation period, season, year, sunspot cycle); location (altitude, latitude, longitude); solar activity (ultraviolet radiation, X-rays, solar plasma, magnetic storms); and processes (diffusion, heat transfer, mass transport, dissociation, photo-ionization). The U.S. Standard Atmosphere (Reference 1) is the best available reference and has been used here for data on molecular pressure, concentration, and mean free path for the various altitudes.

Particulate and gaseous emission from the spacecraft may be either periodic or continuous. Periodic contributions consist of waste dumping and thrustor firings for spacecraft attitude and orbit changes; continuous contributions are provided by the leakage or the diffusion through walls of gaseous materials in sealed compartments or by vacuum desorption of materials.

The ambient constituents form in two regions around the spacecraft: the condensation region and the rarefaction region. The condensation region forms in front of a moving spacecraft as a result of the impingement of neutral ambient particles (molecules and atoms) against its frontal surface. After collision, these particles (which have a thermal velocity much less than the spacecraft velocity) are reflected and form a stagnation zone ahead of the spacecraft. The result is a zone with increased particle concentration. In addition to these reflected particles, this zone contains nonreflected ambient particles and the contribution of particles originating from the spacecraft itself. The last of these will be of greatest concern in the discussions on contamination of the spacecraft surfaces.

The rarefaction region, caused by the spacecraft's sweeping of the ambient particles, forms at the rear of the spacecraft. The length of the region increases with increasing velocity of the spacecraft. The concentration of particles is not dependent on the interaction of the ambient molecules with the spacecraft surface. The region consists mainly of electrons with a velocity much higher than the spacecraft and, hence, which are not affected by its motion. Molecules from spacecraft outgassing and emission will be present in this region; however, since they have velocity vectors directed away 
from the spacecraft velocity vector and will be left behind, they are of no concern unless they are directed against some spacecraft protuberance.

As a result of collision with charged particles, and because of surface emission caused by solar irradiation, a spacecraft will also acquire an electric potential. A brief discussion of this subject and an investigation on the effect of a given potential on an electrically polarized molecule is given in the appendix. It is concluded that its effect on the trajectory and velocity of outgassed molecules is not significant.

In the following, the outgassing of materials in vacuum as a function of time and temperature and the main effluents of that outgassing are reviewed. The concentration of molecules around the spacecraft is determined under the assumption that the molecules from the spacecraft surface do not, by and large, collide with each other. On the contrary, it is assumed that their density distribution around the spacecraft is governed by their collision with ambient molecules. The same calculations are made for the ambient molecules reflected by the spacecraft. Similarly, the fraction of desorbed molecules, which upon collision with ambient molecules lose part of their energy and are reacquired by the oncoming spacecraft, has been estimated. This "returning flux" is used, together with other parameters of gas-surface interaction, to establish the probable degree of contamination on the spacecraft surface. Condensation rates, gas adsorption, column mass densities, molecular densities surrounding the spacecraft, and other parameters are calculated for a number of spacecraft for which outgassing rates have been reported in the literature. Also, the same parameters are calculated for spacecraft whose outgassing during the first hour of vacuum exposure has been estimated.

\section{CONTAMINATION SOURCES-OUTGASSING}

The gases emitted by a spacecraft originate from several sources: material outgassing, leaks from sealed compartments, thrustor firing, and waste dumpings.

Gas leaks from sealed compartments are dictated by the size, path, and configuration of the leak passages and by the pressures in the compartment. Gas emission may last until the gases in the compartment are depleted. Thrustor firings and waste dumpings are controllable in quantity and length of time and are of periodic nature.

Material outgassing, which could be the prime source of contaminant for a scientific satellite, consists of (1) gases evolved from the desorption of gases physically or chemically adsorbed on the material surface, (2) the evaporation and decomposition of gases in solution in the material, and (3) the evaporation or sublimation of the material itself.

The direct evaporation or sublimation of material is a phase change by which a solid or liquid loses material to the gaseous phase. It occurs when the net partial pressure of the evaporant gas above the evaporating surface is less than the equilibrium vapor pressure of the material. (When the opposite conditions exist, condensation of the gas occurs.) The equilibrium saturated vapor pressure of the material, which dictates the rate of evaporation, increases exponentially with temperature. Its expression and others for the calculation of phase changes are given in the discussion of contaminant condensation. The rate of evaporation in vacuum of a material at a given temperature is constant and 
continues until all of the liquid or solid changes to gas. In space applications, the use of materials that may easily evaporate or sublime is avoided, except perhaps in some special applications where the evaporation of the material is intentionally used for a function.

Outgassing of materials in a vacuum has been studied extensively, and theoretical and experimental outgassing rates have been reported in the literature. Several explanations of the outgassing mechanisms have been given; but, in general, material outgassing can be characterized by the following:

(1) Outgassing depends on the nature of the material; for a given material it is a function of the surface and of the atmospheric composition to which the material was exposed prior to its exposure to vacuum.

(2) Outgassing is proportional to the surface area and increases rapidly with the temperature. It decreases slowly with time and apparently never becomes zero at ambient temperature.

(3) At sufficiently low pressures, the outgassing rate is independent of the pressure, i.e., the number of molecules expelled by the surface per unit time does not depend on the pressure above the outgassing surface. This behavior has not been established with complete certainty, but it is valid as a first approximation.

The time dependence of the outgassing is related to the nature of the gas evolved (Reference 2). It may decrease exponentially with time $\left(e^{-t}\right)$, with the square root of the time $\left(t^{-1 / 2}\right)$, or, in many cases, simply directly with time $\left(t^{-1}\right)$. The exponential dependence results from first-order surface desorption; the square-root dependence results from diffusive process. (Both laws are derivable from analytical investigation of the processes involved.) In practice, however, it has been found that these dependences with time do not hold in many cases. Metals outgas according to the $t^{-1}$ law during the first few days; the products consist mainly of $\mathrm{H}_{2} \mathrm{O}, \mathrm{H}_{2}, \mathrm{CO}, \mathrm{CO}_{2}$, and $\mathrm{O}_{2}$. Degassing of glasses follows the $t^{-1 / 2}$ law; the products consist mainly of $\mathrm{H}_{2} \mathrm{O}$ and $\mathrm{CO}_{2}$. Elastomers release gases by diffusion process, so the outgassing follows the $t^{-1 / 2}$ law; the products are often $\mathrm{CO}, \mathrm{CO}_{2}, \mathrm{H}_{2}$, and $\mathrm{H}_{2} \mathrm{O}$. Depending on the thickness of the outgassing materials, permeation may also be present. In this case, the gases adsorbed on the surface enter the material; and because of concentration gradients, they move in the material and emerge on the side of low pressure. The permeation rate reaches a steady state and becomes constant with time. Gaseous hydrogen has the highest permeation through metals, and helium has the highest for glasses. Elastomers, which are not too selective, allow most gases to pass.

All outgassing processes increase rapidly with temperature. As a rule, a 10-percent change in absolute temperature produces a tenfold increase in outgassing (Reference 3 ).

Outgassing rates for several materials have been obtained and are reported in the literature (References 2 and 4), either in tabular forms or graphically. The rates versus time are at ambient temperature and are expressed as air equivalent. Qualitative data obtained from accelerated tests to determine acceptability of materials for space applications are also available* (Reference 5).

*Fisher, A., and Mermelstein, B., "Outgassing Studies on Some Polymer Systems for GSFC Cognizant Spacecraft," NASA-GSFC Document X-735-70-73, February 1970. 
Methods that can be used for establishing outgassing of a system are the conductance method, the pressure-rise method, and loss-of-weight method. With the conductance method, one can calculate the outgassing by employing the relation for the flow, $Q=\triangle P S$. From the pumping speed of the system, $S$, and the pressures obtained in the pumping system with and without the outgassing material, the outgassing $Q$ can be calculated. With the method of pressure rise, one isolates the pumping system containing the material and obtains the rate of pressure increase. The outgassing is obtained from $V d p / d t=Q$, comparing the outgassing for the chamber with and without the outgassing material. The determination of the weight lost by the material exposed to vacuum is less reliable and more difficult to perform.

Another laborious method for estimating the outgassing of a spacecraft is to add all the calculated outgassings of each surface and component of the spacecraft. This requires an estimate of the surface areas and a knowledge of the outgassing rate for each component. In all cases, the nature of the outgassing must be obtained by mass spectrometry or other physical or chemical analyses.

The outgassing $Q$ is commonly expressed in torr-liters per second (torr-1/s), where

$$
1 \text { torr }-1 / \mathrm{s}=0.133 \mathrm{~N}-\mathrm{m} / \mathrm{s} \text {. }
$$

To express this rate in terms of molecules per unit time $\dot{N}$, one uses the gas law relation

$$
Q=P V=\dot{N} K T \quad\left(\mathrm{~N}-\mathrm{m}-\mathrm{s}^{-1}\right)
$$

so that

$$
\left.\dot{N}=Q / K T \quad \text { (molecules-s }{ }^{-1}\right),
$$

where $K=1.38 \times 10^{-23} \mathrm{~J}-\mathrm{K}^{-1}=1.04 \times 10^{-22}$ torr-1- $\mathrm{K}^{-1}$ is Boltzmann's constant and $T$ is the temperature in kelvins. To express the rate in terms of mass per unit time, $\dot{m}$, one uses

$$
\dot{m}=M \dot{N} / A=Q M / K T A \quad\left(\mathrm{~g}_{-} \mathrm{s}^{-1}\right)
$$

where $M$ is the molecular weight and $A$ is Avogadro's number.

\section{CHARACTERISTICS OF THE GAS AROUND AN ORBITING SPACECRAFT}

The flow past an orbiting spacecraft is of the free molecular nature since the mean free paths of the molecules at orbiting altitudes are larger than the spacecraft dimensions. The molecules move independently of each other, and there are no aerodynamic effects (such as boundary layers) in the immediate vicinity of the spacecraft. A kinetic theory that considers the medium as an aggregate of individual particles must be used to describe their behavior.

Mean free path can be defined as the mean distance a molecule must travel before it encounters another molecule. It is a function of the number of molecules per unit volume and of the diameter of the molecules. For an orbiting spacecraft, one can distinguish three mean free paths: the mean free path of the ambient molecules, $\lambda_{0}$, the mean free path of the molecules desorbed by the spacecraft, $\lambda_{D}$, and the mean free path of the ambient molecules which recoil from the spacecraft upon collision with it, $\lambda_{R}$. The ambient mean free path $\lambda_{0}$ increases with altitude; its value for various altitudes as given in Reference 1 is shown in Figure 1. A discussion of the other two follows. 


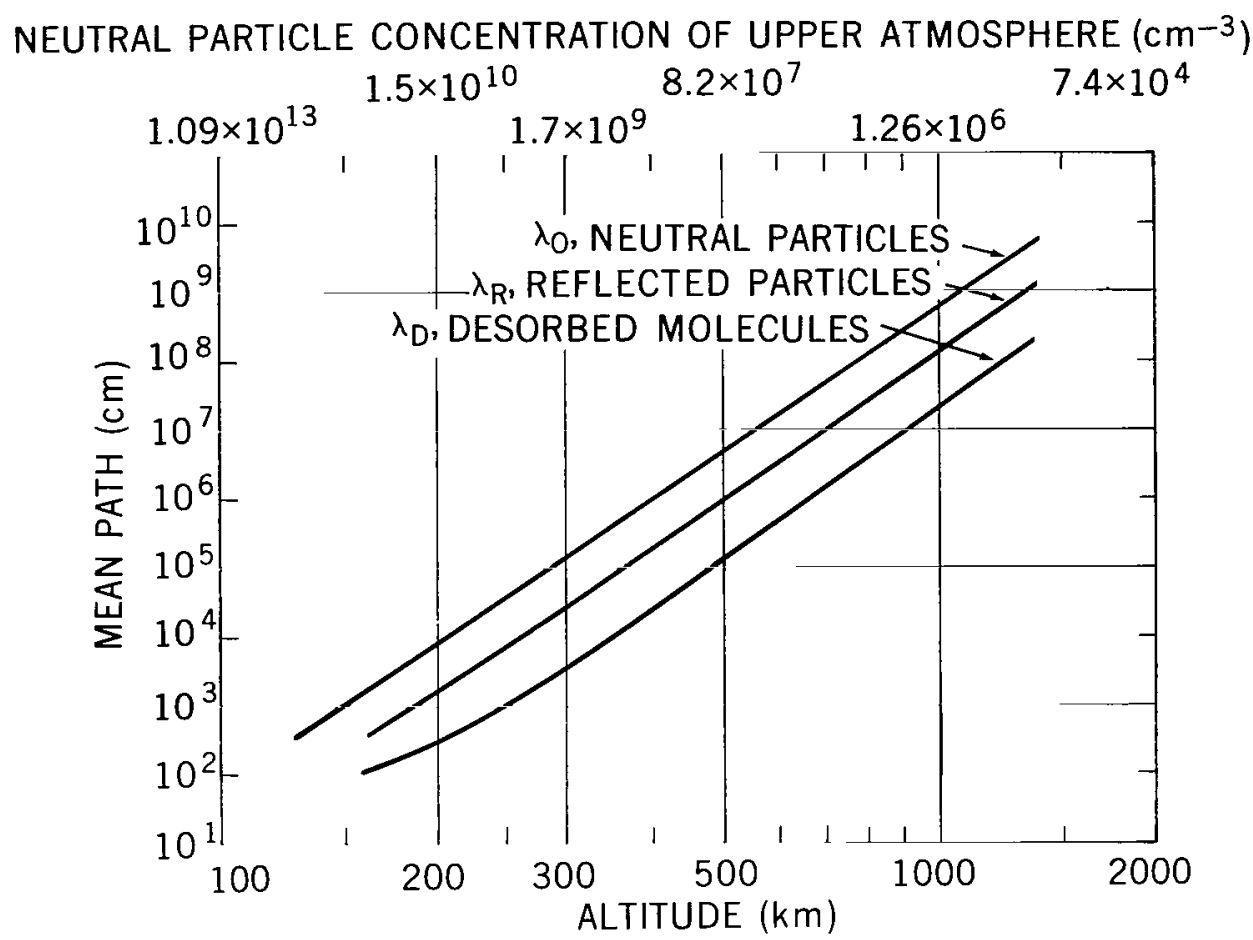

Figure 1-Mean free paths vs. altitude. Assume the average velocity of the reflected particles to be one-third of the orbital velocity $\left(v_{R}=v_{0} / 3\right)$ and the mean thermal velocity of the desorbed molecules $v_{D}$ to be $4 \times 10^{4} \mathrm{~cm}^{-1}$.

\section{Desorbed Molecules}

The molecules emitted by the spacecraft travel a mean distance $\lambda_{D}$ before colliding with ambient molecules. According to Reference 6 , this distance is less than $\lambda_{0}$ because the spacecraft moves into the wake of the outgoing molecules. Mirtov (Reference 6) calls this distance the "relative mean free path" and defines it as

$$
\lambda_{D}=K \lambda_{0},
$$

where $K$ depends on the spacecraft velocity $v_{0}$, the velocity of the desorbed molecule $v_{D}$, and the angle $\phi$ between the vectors $\nu_{0}$ and $\nu_{D}$. He states that $K$ can be adequately approximated by

$$
K=\frac{v_{D}}{v_{0}+v_{D}} \cos ^{2} \Psi+\frac{v_{D}}{\left(v_{0}^{2}+v_{D}^{2}\right)^{1 / 2}} \sin ^{2} \Psi,
$$

where the angle $\Psi$ is given by

$$
\tan ^{2} \Psi=\frac{4 \phi^{2}}{\pi^{2}-4 \phi^{2}}
$$

Accordingly, for the extreme conditions of $\phi=0$ and $\phi=\pi / 2$, the values of $K$ are

$$
K_{0}=\frac{v_{D}}{v_{D}+v_{0}}
$$


and

$$
K_{\pi / 2}=\frac{v_{D}}{\sqrt{v_{D}^{2}+v_{0}^{2}}}
$$

For near-earth orbits, $v_{D} \ll v_{0}$. Hence, the two expressions practically coincide, and for simplicity, $K_{0}$ can be used in the calculations. This expression meets the conditions for a stationary spacecraft (i.e., $v_{0}=0$ ): $K_{0}=1$, and the mean free path of the desorbed molecules, $\lambda_{D}$, is equal to $\lambda_{0}$. The relative mean free path for $\phi=0$ is then

$$
\lambda_{D}=\frac{v_{D}}{v_{0}+v_{D}} \lambda_{0}
$$

which is plotted in Figure 1. The value for the orbital velocity was obtained from

$$
v_{0}=\sqrt{\frac{r_{0}}{r}} \sqrt{g_{0} r_{0}}=7.9 \sqrt{\frac{r_{0}}{r}}, \quad\left(\mathrm{~km}-\mathrm{s}^{-1}\right)
$$

where $g_{0}$ is the acceleration of gravity, $r_{0}$ is the radius of the earth, and $r$ is the radius of the orbit from the center of the earth. The velocity of the desorbed molecules was taken as an average of the mean thermal velocity of molecules with molecular weights of 32 to 48 and temperatures of 250 to $300 \mathrm{~K}$ :

$$
v_{D}=\sqrt{\frac{8 K T}{\pi M}} \approx 4 \times 10^{4} \mathrm{~cm}-\mathrm{s}^{-1}
$$

Therefore, for the values of $v_{0}$ experienced in near space, the relative free path is approximately $1 / 20$ of the ambient mean free path.

\section{Reflected Particles}

In addition to the molecules desorbed from the spacecraft, ambient molecules that recoil upon collision with the spacecraft must be considered. According to Reference 3, these molecules are $\mathrm{H}$, $\mathrm{O}, \mathrm{O}_{2}$, and $\mathrm{N}_{2}$ at temperatures varying from $900 \mathrm{~K}$ at night to $1600 \mathrm{~K}$ during the day. They have the following average velocities (in $\mathrm{km}^{-1}$ at $1500 \mathrm{~K}$ ): 6.1 for $\mathrm{H}, 1.15$ for $\mathrm{N}_{2}, 1.08$ for $\mathrm{O}_{2}, 1.5$ for $\mathrm{O}$, and 1.6 for N. According to the same reference, these particles reflect diffusely from the spacecraft with an average departure velocity $V_{r}=1 / 3 v_{0}$. Consequently, their relative mean free paths, for the relation in Equation 8 and assuming reflection parallel to satellite motion, is given approximately by

$$
\lambda_{R}=\frac{V_{r}}{V_{r}+v_{0}} \lambda_{0}=1 / 4 \lambda_{0}
$$

This value of $\lambda_{R}$ as a function of altitude is shown in Figure 1.

The magnitude of the average speed of the reflected particles can be related to incident velocity $V_{i}$ and the surface wall temperature $T_{s}$ through the accommodation coefficient $\alpha_{s}$ : 


$$
\frac{V_{r}}{V_{i}}=\sqrt{1+\alpha_{s}\left(\frac{T_{s}}{T_{i}}-1\right)}=\sqrt{1-\alpha_{s}} \text { for } \frac{T_{s}}{T_{i}} \ll 1,
$$

where $T_{i}$ is the temperature of the incident molecule. The meaning of the coefficient $\alpha_{s}$ will be discussed in some detail later when we seek to determine the adsorption of the returned molecules on the spacecraft surface. The velocity of the reflected molecules enters into the calculation of the parameters of the so-called cloud surrounding the spacecraft and relates to the ability of these particles to ionize the ambient molecules with which they collide. The values of the parameters obtained using the above value for the velocity will be compared with those from another method; they are found to be in good agreement.

\section{DENSITY OF THE MOLECULES LEAVING THE SPACECRAFT}

Assuming that the density of the molecules originating from a spherical spacecraft is such that the majority of the molecules do not collide with each other, and assuming that the trajectory is straight until the collision with ambient molecules, one can reason as follows (Reference 6):

The density $n$ in a spherical shell of thickness $d$ at radial distance $x$ from a spacecraft of radius $R$ is

$$
n=\frac{N_{x}}{V} t=\frac{N_{x}}{V} \frac{d}{v_{m}},
$$

where $N_{x}$ is the number of molecules per unit time entering the shell at $x, t$ is the time required by the molecules to cross distance $d$ at velocity $v_{m}$, and $V=4 \pi(R+x)^{2} d$ is the approximate volume of the shell. If $N_{D}$ (molecules-s ${ }^{-1}$ ) is the number of original molecules coming from the surface, then according to the "survival relation," the number of molecules reaching radial distance $x$ is given by

$$
N_{x}=N_{D} e^{-x / \lambda} \text {, }
$$

where $\lambda$ is the mean free path of the ambient gas and is independent of the angle $\phi$ and distance $x$. With this substitution in Equation 12, the density $n$ becomes

$$
n=\frac{N_{D} e^{-x / \lambda}}{4 \pi(R+x)^{2} v_{m}} .
$$

At the surface of the spacecraft (i.e., $x=0$ ), the density of the molecules leaving the spacecraft is

$$
n_{x=0}=\frac{N_{D}}{4 \pi R^{2} v_{m}}
$$

\section{DENSITY OF MOLECULES LEAVING AND RETURNING TO THE SPACECRAFT}

Molecules leaving the spacecraft with drist velocities equal to the vector sum of the spacecraft and desorption velocities collide, at some distance from the spacecraft, with ambient molecules which can be considered immobile. After collision, the drift velocity of these desorbed molecules is less than the spacecraft velocity. 
Desorbed molecules that collide in a shell of thickness $\Delta x$ at distance $x$ from the spacecraft surface can be obtained as follows (Reference 6):

The number of molecules $N_{x}$ reaching distance $x$ without suffering collision is governed by

$$
N_{x}=N_{D} e^{-x / \lambda} .
$$

The number reaching distance $x+\Delta x$ is, from the same equation,

$$
N_{x+\Delta x}=N_{D} e^{-x / \lambda} e^{-\Delta x / \lambda}
$$

The difference between these two values represents the number of desorbed molecules that have collided with ambient molecules in the shell of volume $4 \pi(R+x)^{2} \Delta x$. This difference, for $\lambda \gg \Delta x$, is

$$
\begin{aligned}
\Delta N & =N_{D} e^{-x / \lambda}\left(1-e^{-\Delta x / \lambda}\right) \\
& =\frac{N_{D} e^{-x / \lambda}}{\lambda} \Delta x .
\end{aligned}
$$

Dividing this expression by the shell area, $4 \pi(R+x)^{2}$, one obtains the number of collisions occurring at distance $x$ in a volume having a unit area as its base and $\Delta x$ as its thickness; i.e.,

$$
\Delta n=\frac{N_{D} e^{-x / \lambda}}{4 \pi(R+x)^{2}} \frac{\Delta x}{\lambda} .
$$

In the projected volume in the direction of the spacecraft displacement, the molecules $\Delta n$ in each $\Delta x$ can be considered to be moving toward a stationary spacecraft at a velocity $v_{n}$ equal to the difference in velocity before and after collision. The total number of these molecules $N^{\prime \prime}$ striking the unit surface of the spacecraft is the sum of the molecules $\Delta n$ originating at the various distances, $0<x<\infty$, in front of the spacecraft; i.e.,

$$
\begin{aligned}
N^{\prime \prime} & =\int_{0}^{\infty} d n=\int_{0}^{\infty} \frac{N_{D} e^{-x / \lambda}}{4 \pi(R+x)^{2} \lambda} d x \\
& \approx \frac{N_{D}}{4 \pi \lambda R} \text { for } \lambda \gg R .
\end{aligned}
$$

At a distance $a$ in front of the satellite, the number of returning molecules is

$$
\begin{aligned}
N_{a}^{\prime \prime} & =\int_{a}^{\infty} d n=\int_{a}^{\infty} \frac{N_{D} e^{-x / \lambda}}{4 \pi(R+x)^{2} \lambda} d x \\
& =\frac{N_{D}}{4 \pi \lambda} \frac{e^{-a / \lambda}}{(R+a)} .
\end{aligned}
$$

Since the flux per unit area is $n^{\prime \prime} v_{n}=N^{\prime \prime}$, the apparent density $n^{\prime \prime}$ is given by

$$
n^{\prime \prime}=\frac{N^{\prime \prime}}{v_{n}}=\frac{N_{D}}{4 \pi \lambda v_{n}} \frac{1}{R} \text {. }
$$


The integration in Equation 20 was made for the molecules that suffer collision in front of the spacecraft along the axis of motion and in a unit cross-section column. Scattering has been disregarded under the assumption that molecules scattered out of the column are replaced by molecules scattered in from other columns. In view of this, it is felt that a large error has not been introduced in this calculation.

Comparing Equations 15 and 22, the ratio of the molecules returned to those that left is

$$
\frac{n^{\prime \prime}}{n_{\chi=0}}=\frac{R}{\lambda} \frac{v_{m}}{v_{n}} \text {. }
$$

\section{EFFECT OF ELECTRIC POTENTIAL}

Thus far, the discussions have been based on the behavior of neutral particles. It may happen that when the spacecraft acquires an electric potential sufficient to create an appreciable electrostatic field, some molecules may become electrically polarized or become ionized if they experience a collision with high-energy particles. In these cases, the gas kinetic equation must include the effect of electric and magnetic forces. Some of the parameters that affect the potential will only be mentioned here; more detailed treatment is given in the appendix and in References 7 through 11 .* Briefly, it can be stated that the electrostatic force will not significantly disturb the motion of the molecules.

The potential of a metallic body in a plasma is determined by the balance of electric currents produced by collision with charged particles and by emission, through surface irradiation, of electrons. The general expression is

$$
\phi(t)=\frac{1}{C} \int_{0}^{t} \Sigma I d t+\phi(0)
$$

where $C$ is the capacitance of the metallic body (the spacecraft) and $I$ represents the various currents (e.g., currents produced by absorption of plasma electrons, by absorption of electrons as the spacecraft passes through radiation belts, and so forth).

At altitudes above the ionosphere, the photoelectron current dominates, and although it can be quite substantial, the negative charge that forms around the spacecraft acts as a shield against further electron loss, preventing further increase of positive potential. At altitudes corresponding to the radiation belts, the current produced by radiation electrons is appreciably larger than that produced by protons; it even exceeds the photoelectron current, and the spacecraft may acquire a negative potential. In the ionosphere, the currents produced by the absorption of plasma electrons $I_{e}$ and by plasma ions $I_{i}$ are most intense. These may be approximated by

$$
I_{e}=\frac{\pi R^{2}}{2} e v_{e} n_{e} \exp \frac{-\phi_{0} e}{K T},
$$

\footnotetext{
*Also see Whipple, C. E., "The Equilibrium Electric Potential of a Body in the Upper Atmosphere and in Interplanetary Space," NASA-GSFC Document X-615-65-296, June 1965.
} 
where $R$ is the spacecraft radius; $e$, the charge of electron; $v_{e}$, the mean electron velocity; $n_{e}$, the electron concentration; and $\phi_{0}$, the existing spacecraft potential; and

$$
I_{i}=\pi R^{2} v_{0} n_{i} e,
$$

where $v_{0}$ is the spacecraft velocity and $n_{i}$ is the ambient ion concentration. The negative potential obtained by equating these two currents is a few volts.

The general equation of current balance has been solved for the values of $n_{i}, T, v$, and so forth, that are possible in the upper atmosphere and in interplanetary space. A potential of about $-20 \mathrm{~V}$ can be obtained for a 65 -cm-radius spacecraft if $T \approx 10^{3}$ to $10^{4} \mathrm{~K}$ and $n_{i}=10^{3} \mathrm{~cm}^{-3}$. With $n_{i}=10^{5} \mathrm{~cm}^{-3}$, the same spacecraft would have a potential of -5 to $-3 \mathrm{~V}$.

The force $F$ exerted on a molecule (with dipole moment $M$ ) at a distance $r$ from a sphere of radius $a$ and surface potential $V_{0}$ is

$$
F=M \frac{2 V_{0} a}{r^{3}}
$$

For a water molecule $\left(M=6 \times 10^{-28} \mathrm{C}-\mathrm{cm}\right)$ located on the surface of a sphere of radius $0.5 \mathrm{~m}$ and surface potential $10 \mathrm{~V}$, the force is

$$
\begin{aligned}
F & =\left(6 \times 10^{-28}\right) \frac{2 \times 10}{(50)^{2}} \\
& =4.8 \times 10^{-28} \mathrm{~N} .
\end{aligned}
$$

The corresponding escape velocity is $1.26 \times 10^{-1} \mathrm{~m}-\mathrm{s}^{-1}$, neglecting that part of the energy used to rotate the molecule. Compared with the thermal velocity of water at $273 \mathrm{~K}\left(5.5 \times 10^{2} \mathrm{~m}-\mathrm{s}^{-1}\right)$, this value leads one to conclude that the molecule will be affected very little by the field and that calculations disregarding its effect can be considered acceptable.

\section{APPLICATION}

The above equations permit calculations of several parameters describing the environment surrounding the spacecraft. With the appropriate value for $\lambda$ and $\nu$, we can calculate the concentrations, pressures, and fluxes at various distances from an orbiting spacecraft, provided we have the ambient parameters and a knowledge of the molecules desorbed by the spacecraft. As will be shown, we will also be able to calculate the optical thickness of the environment.

\section{Desorbed Molecules-Condensation Region}

The concentration of the molecules uniformly outgassed from the surface of a spherical spacecraft at a distance $x$ from this surface is given by Equation 14. Inserting the value of $\lambda=\lambda_{D}=\left[v_{D} /\left(v_{0}+v_{D}\right)\right] \lambda_{0}$, we get 


$$
n_{D}=\frac{N_{D}}{4 \pi v_{D}} \frac{\exp \left(-\frac{v_{D}+v_{0}}{v_{D}} \frac{x}{\lambda_{0}}\right)}{(R+x)^{2}} \quad \text { (molecules-cm }{ }^{-3} \text { ). }
$$

Since $P=n K T$, this can be also considered an equivalent pressure:

$$
P_{D}=\frac{N_{D} K T}{4 \pi v_{D}} \frac{\exp \left(-\frac{v_{D}+v_{0}}{v_{D}} \frac{x}{\lambda_{0}}\right)}{(R+x)^{2}}
$$

Parametric plots of these equations are shown in Figure 2. The value of $v_{D}$, the thermal velocity of the desorbed molecules, has been held constant at $4 \times 10^{4} \mathrm{~cm}-\mathrm{s}^{-1}$. The orbiting velocity $v_{0}$ and the ambient mean free path $\lambda_{0}$ are functions of altitude. Knowing $N_{D}$ expressed in any form as indicated by Equations 1, 2, and 3, we can read the pressure and concentration as a function of the distance, altitude, and size of the spacecraft. Figure 2 shows that at low altitude, the density resulting from outgassing products drops quite rapidly at a distance of about $10 \mathrm{~cm}$ from the spacecraft. At high altitudes, the drop is very gradual, becoming an order of magnitude lower at about 2 to $3 \mathrm{~m}$ from the surface.

Equation 28 can be transformed to flux; i.e.,

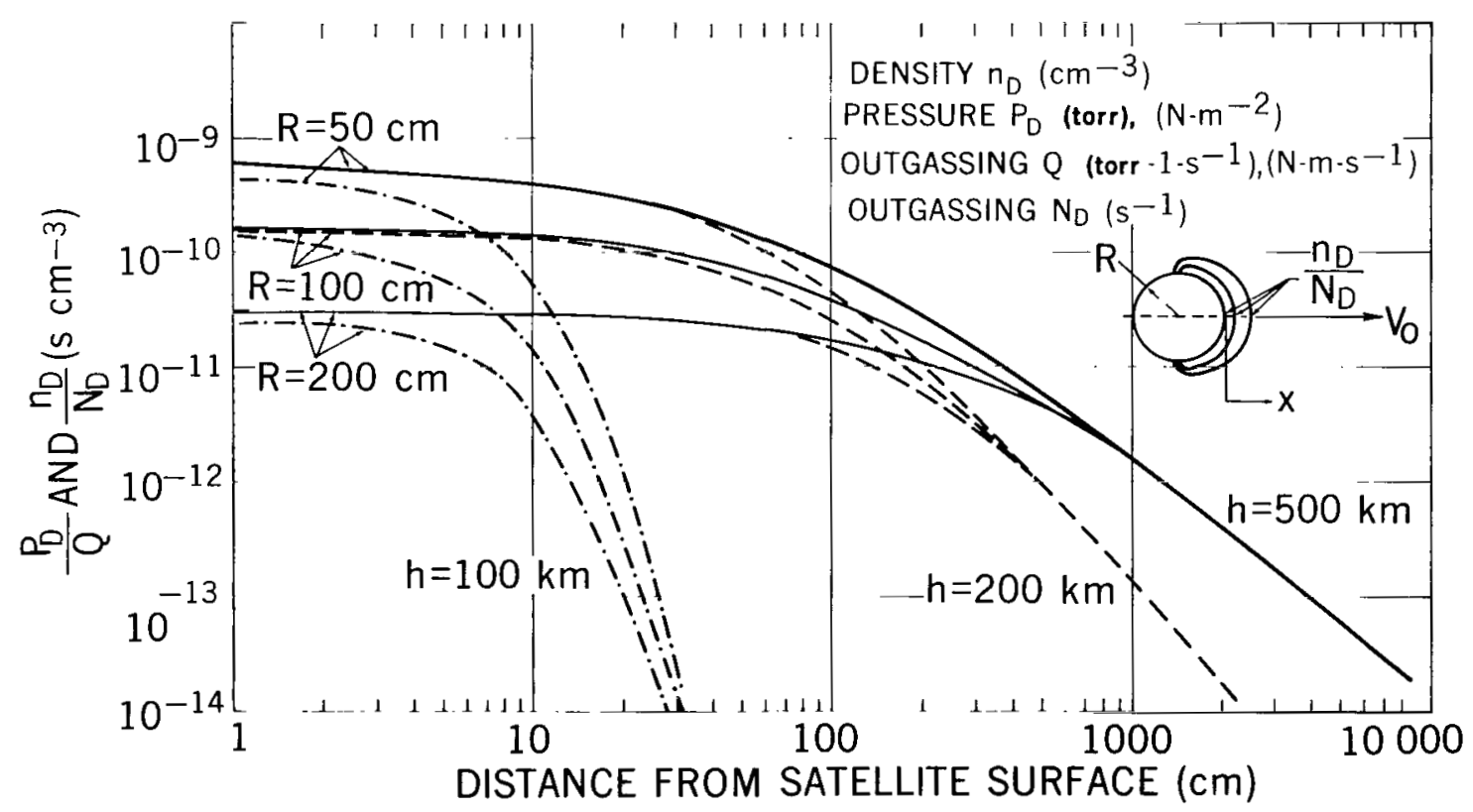

Figure 2-Pressure and density produced by outgassing vs. distance from the spacecraft surface. 


$$
\phi_{D}=\frac{N_{D} \exp \left(-\frac{v_{D}+v_{0}}{v_{D}} \frac{x}{\lambda_{0}}\right)}{4 \pi(R+x)^{2}} \quad \text { (molecules-cm }{ }^{-2}-\mathrm{s}^{-1} \text { ) }
$$

since $\phi=n_{D} v_{D}$.

\section{Reflected Molecules-Condensation Region}

The number of ambient molecules reflected by the spacecraft is $N_{R}=A v_{0} n_{0}$, where $A=\pi R^{2}$ is the spacecraft cross section, $v_{0}$ is the orbital velocity, and $n_{0}$ is the ambient, neutral particle concentration. Accounting for the fact that the molecules are propagated only in the front hemisphere (Reference 6) and that $\lambda=\lambda_{R}=1 / 4 \lambda_{0}$ (Equation 11) and $v_{D}=v_{r}=1 / 3 v_{0}$, the concentrations and the pressures are given by Equation 14 as

$$
\frac{n_{R}}{n_{0}}=\frac{P_{R}}{P_{0}}=\frac{3 e^{-4 \alpha R / \lambda_{0}}}{2(1+\alpha)^{2}}
$$

where $\alpha=x / R$.

At the spacecraft surface, $x=0$ and $n_{R} / n_{D}=P_{R} / P_{0}=3 / 2$. In these equations, $P_{0}$ is the undisturbed ambient pressure. The density and pressure ratios have been plotted in Figure 3 . The density and pressure ratio has been shown as a function of distance $x / R$ for different altitudes and spacecraft radii $(0.5,1.0$, and $2.0 \mathrm{~m})$. At low altitudes, the $n_{R}$ contribution becomes about $0.1 n_{0}$ within $0.5 R$ distance from the spacecraft. At altitudes greater than $200 \mathrm{~km}$, the contribution is not too sensitive to the radius, and it decays slowly with distance; it is about $0.1 n_{0}$ at about $2 R$. Because of the assumptions made in the calculation of this contribution, we have sought assurance from another source. Reference 7, using a different method and accounting for diffuse reflection, calculates the following total concentrations at the various distances:

$\begin{array}{cc}\begin{array}{c}\text { Distance } \\ (\alpha=x / R)\end{array} & \begin{array}{c}\text { Total Concentration } \\ \left(n / n_{0}\right)\end{array} \\ 0.1 & 2.5 \\ 0.2 & 2.0 \\ 1.0 & 1.5 \\ 3.0 & 1.1\end{array}$

Since the total concentration is the sum of the ambient and the reflected concentration (i.e., $\left.n / n_{0}=1+n_{R} / n_{0}\right)$, the present calculation compares favorably with that of Reference 7 .

\section{Returning Molecules-Condensation Region}

Equation 22 indicates the concentration of outgassed molecules that have collided with the ambient molecules and returned to the spacecraft. Substituting the value of $\lambda=\lambda_{D}=\left[v_{D} /\left(v_{D}+v_{0}\right)\right] \lambda_{0}$, it reduces to 


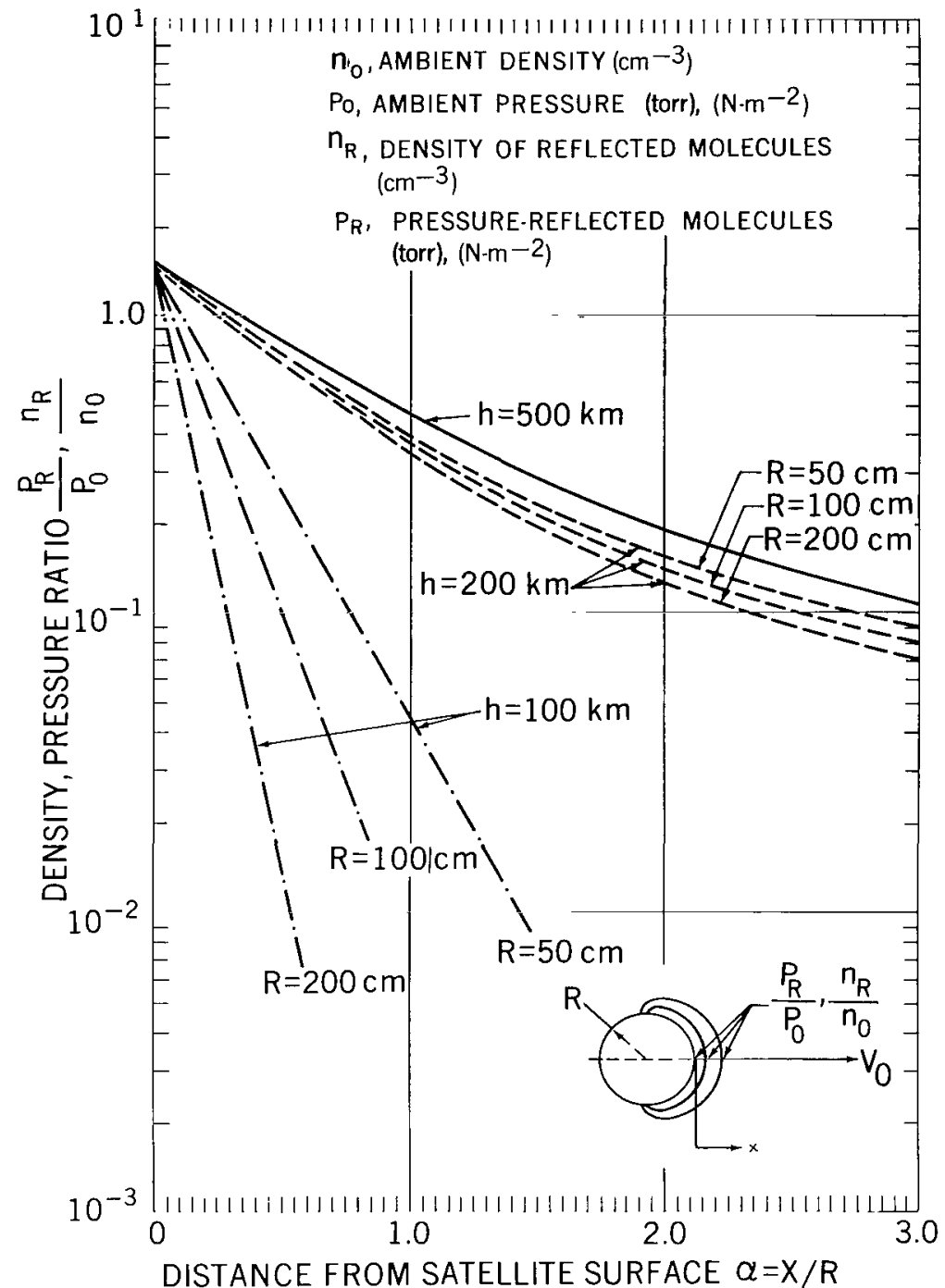

Figure 3-Pressure and density produced by reflected ambient molecules in the condensation region vs. distance from the spacecraft surface.

$$
\frac{n^{\prime \prime}}{N_{D}}=\frac{P^{\prime \prime}}{K T N_{D}}=\frac{1+\frac{v_{0}}{v_{D}}}{4 \pi R \lambda_{0} v_{n}} \quad\left(\mathrm{~s}-\mathrm{cm}^{-3}\right),
$$

where $N_{D}$ (molecules-s ${ }^{-1}$ ) can be expressed in terms of mass per second. Using Equation 22, we may also estimate this concentration or pressure as a function of the concentration and pressure of the molecules leaving; i.e., 


$$
\frac{n^{\prime \prime}}{n_{D}}=\frac{P^{\prime \prime}}{P_{D}}=\frac{R\left(\frac{v_{0}}{v_{D}}+1\right) v_{D}}{\lambda_{0} v_{n}} .
$$

The equivalent equation for the ratio of flux can also be written. The flux of returning molecules is

$$
\phi^{\prime \prime}=n^{\prime \prime} v_{n}=\frac{N_{D}\left(1+\frac{v_{0}}{v_{D}}\right)}{4 R \pi \lambda_{0}} \quad \text { (molecules-cm }{ }^{-2}-\mathrm{s}^{-1} \text { ), }
$$

which, divided by $\phi_{D}$ (Equation 30) taken for $x=0$ (i.e., $\phi_{D}=N_{D} / 4 \pi R^{2}$ ) gives the ratio of the flux of molecules returning to the surface to that leaving the surface:

$$
\frac{\phi^{\prime \prime}}{\phi_{D}}=\frac{R}{\lambda_{0}}\left(\frac{v_{0}}{v_{D}}+1\right) \text {. }
$$

In order that we may compute Equations 32 and 33, it is necessary to estimate the velocity of the returning molecules, $v_{n}$. According to Reference 6 , in an elastic collision with an environmental molecule which can be considered immobile, the molecule escaping the spacecraft surface loses, on the average, half of its velocity and, in inelastic collision, even more. Because of this, the molecule either lags behind the satellite or, if collision occurs close to the satellite and the molecule has time to reach the front surface, settles on it. From this, and the fact that the escaping absolute velocity is $v_{0}+v_{D}$, one can estimate the velocity $v_{n}$ to be about $1 / 2 v_{0}$. Figure 4 is a plot of Equation 32 using this value for $v_{n}$. It indicates that the returning pressure or density resulting from a known outgassing decreases quite rapidly with altitude and becomes approximately constant at altitudes of $1000 \mathrm{~km}$ or more. Also, the concentration is higher for smaller spacecraft diameters.

Figure 5 is a plot of Equation 33, again using $v_{n}=1 / 2 v_{0}$. As expected, the density ratio at the surface decreases rapidly with altitude, reaching a practically constant value at $1000 \mathrm{~km}$ or more, and increases with the radius.

Figure 4 shows also the flux of the returning molecules as a function of the altitude and spacecraft radius. Knowing the outgassing value $\left(N_{D}, Q\right)$, we can determine this flux, which under appropriate conditions can be the source of contamination. Again, it is very much a function of altitude, becoming practically constant and apparently small at altitudes greater than $1000 \mathrm{~km}$. Also, large spacecraft have a smaller return flux than smaller ones.

Figure 5 is also a plot of Equation 35; the flux is given as a function of the outgoing flux.

Figure 6 shows the flux of returning molecules versus distances from the satellite as a fraction of the total returning flux at the surface. This was obtained by taking the ratio of Equations 21 and 20

$$
\frac{N_{a}^{\prime \prime}}{N^{\prime \prime}}=\frac{R}{R+a} e^{-a / \lambda},
$$

which is valid also for density and flux ratios. It can be seen that the flux versus distance diminishes more rapidly for smaller radius satellites than for larger ones, and more rapidly at lower altitudes 


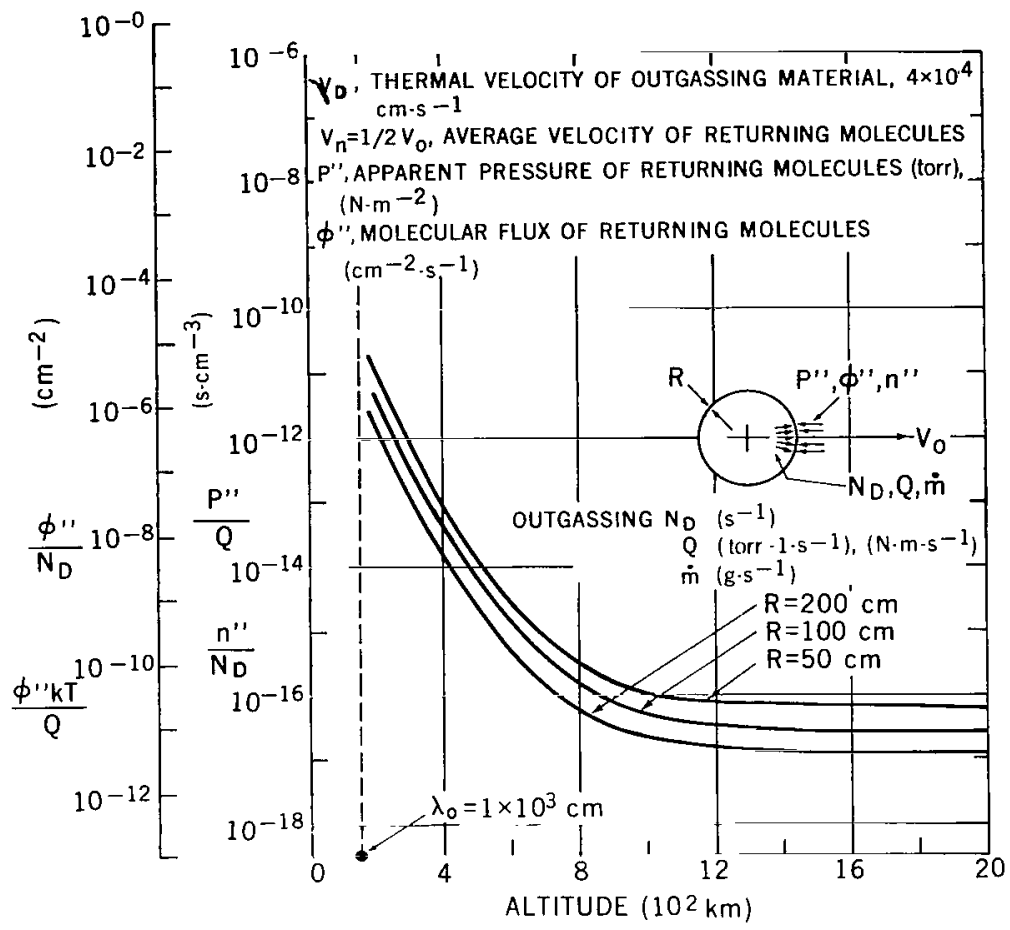

Figure 4-Density, pressure, and flux at the spacecraft surface, produced by outgassed molecules returning to the spacecraft, vs. altitude (for $\lambda_{0}>21 \mathrm{R}$ ).

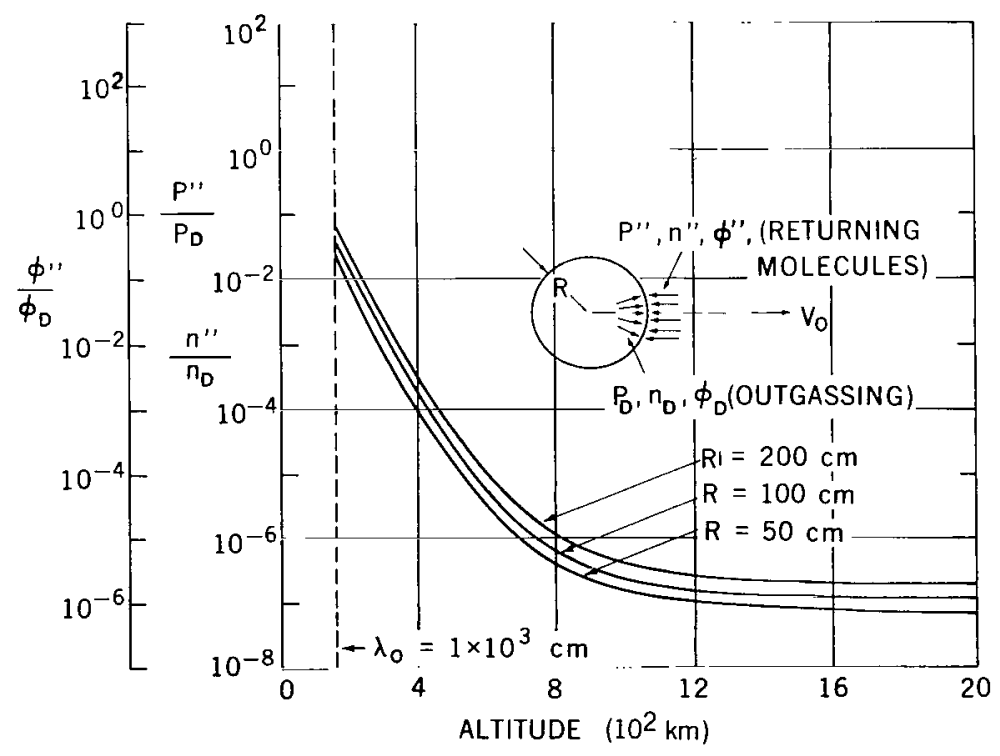

Figure 5-Density, pressure, and flux ratios at the spacecraft surface, produced by outgassed molecules returning to the satellite (for $\left.\lambda_{0}>21 R\right)$. 


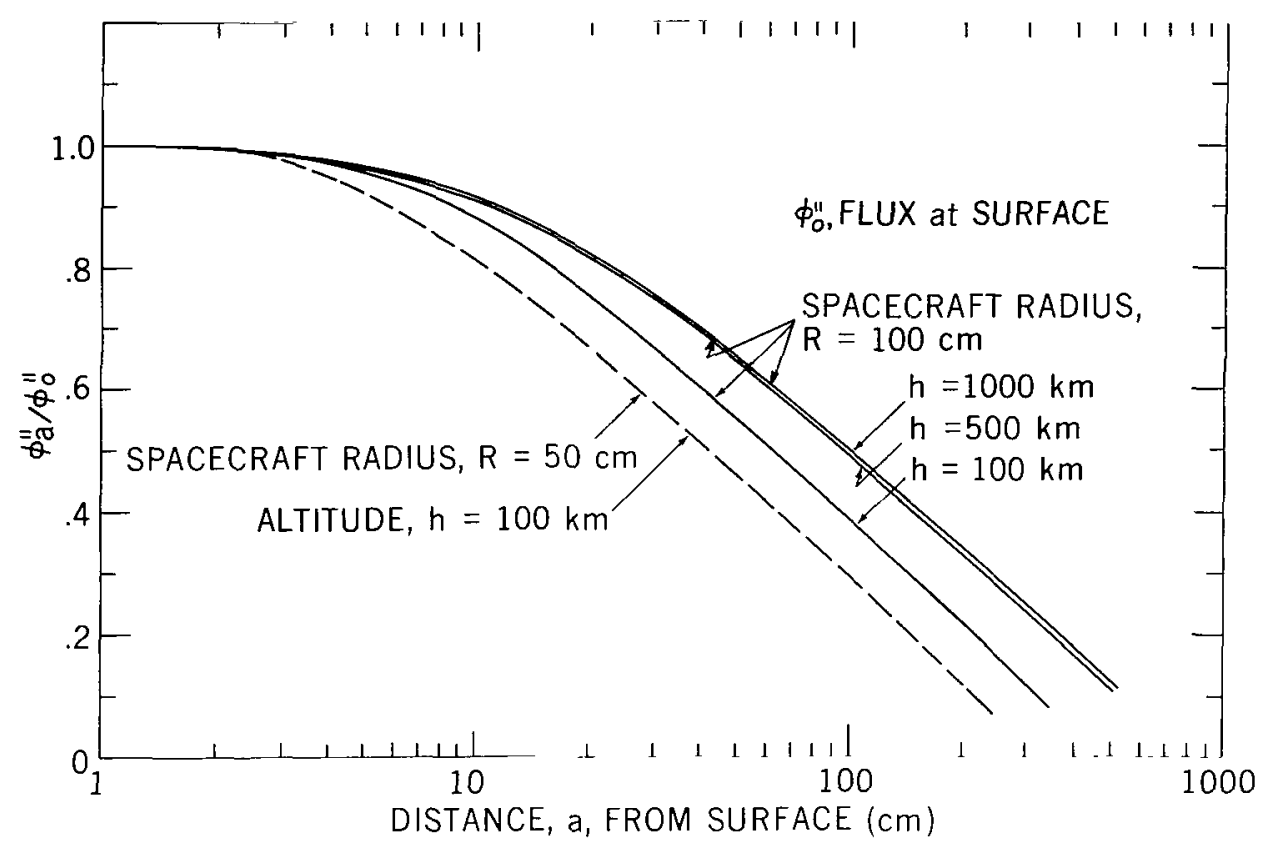

Figure 6-Returning molecules, flux ratio vs. distance from the surface.

than at higher ones. At 2 to 3 radii away, the returning flux is an order of magnitude lower than the flux at the satellite surface.

\section{Light Scattering-Optical Thickness}

Optical observation from a spacecraft may be affected by photon scattering from the molecule cloud, particulate matter, or surface contamination on optical elements. This may be especially severe when observing dim light sources. The brightness of material surrounding a spacecraft [which has often been reported by astronauts (Reference 2)] is produced by light scattering. This is dependent on the mass column density $M_{S}$, and the mass scattering function (molecular absorption cross section) $\sigma$, for the particular molecules of the column and the radiation wavelength.

Mass column density $M_{S}$ can be determined by integrating Equation 14 from zero to infinity. In fact, this equation, using $\dot{m}\left(\mathrm{~g}-\mathrm{s}^{-1}\right)=N_{D} M / A$ for the outgassing, gives (for $\lambda \gg R$ )

$$
\begin{aligned}
M_{S} & =\frac{\dot{m}}{4 \pi v_{m}} \int_{0}^{\infty} \frac{e^{-x / \lambda}}{(R+x)^{2}} d x \\
& \approx \frac{\dot{m}}{4 \pi v_{m}} \frac{1}{R} \quad\left(\mathrm{~g}-\mathrm{cm}^{-2}\right) .
\end{aligned}
$$

This is the same expression Reference 13 obtains using a different method. The product $M_{S} \sigma$ provides an explicit expression for the optical thickness of the molecular debris surrounding a spacecraft. 


\section{RAREFACTION REGION}

As mentioned previously, a rarefaction region is created behind a moving spacecraft by the sweeping action of the vehicle. The length of this region increases with increasing spacecraft velocity $v_{0}$ and is approximately (Reference 7 )

$$
d \approx R \frac{v_{0}}{v},
$$

where $v=\sqrt{2 K T / M}$ is the probable thermal velocity of the ambient molecules. Reference 7, assuming a Maxwellian velocity distribution of the ambient molecules, arrives at the following exponential function for the density along the axis of motion and behind the spacecraft:

$$
\frac{n}{n_{0}}=\exp \left[-\frac{M \nu_{0}^{2}}{2 K T}\left(\frac{R}{x}\right)^{2}\right] .
$$

This expression gives the following density ratios for a vehicle moving at $v_{0}=8 \mathrm{~km}-\mathrm{s}^{-1}$ in ambient

\begin{tabular}{|c|c|}
\hline $\begin{array}{c}\text { Distance } \\
(x / R) \\
\end{array}$ & $\begin{array}{l}\text { Density } \\
\left(n / n_{0}\right) \\
\end{array}$ \\
\hline 5 & 0.1 \\
\hline 10 & 0.5 \\
\hline 15 & 0.75 \\
\hline 25 & 0.9 \\
\hline
\end{tabular}
molecules moving at $v=1 \mathrm{~km}-\mathrm{s}^{-1}$.

\section{CONTAMINATION DUE TO RETURNING FLUX}

The flux of returning molecules may impinge on surfaces or openings which may or may not be outgassing. In the case of outgassing surfaces, the net outgassing of the surface is reduced. For nonoutgassing surfaces, molecular layers will accumulate. The accumulation may take the form of material condensation or simply the adsorption of a number of molecules or monolayers on the surface. Either of the two formations may be detrimental to the operation of instrument or experiment packages. Both phenomena will be considered.

\section{Surface Adsorption of the Contaminant}

If the pressure exerted by the contaminant gas on the surface is less than the saturation vapor pressure of the same contaminant on the surface, a few monolayers or a fraction of one may form as an adsorbate. This is a surface phenomenon where molecules are held on the surface by forces of physical nature. An equilibrium between molecules arriving and leaving the surface is established when

$$
\sigma=\gamma \phi \tau,
$$


where $\sigma$ is the number of adsorbed molecules per unit area, $\phi$ is the flux of impinging molecules, $\gamma$ is the sticking coefficient, and $\tau$ is the average time a molecule resides on the surface. The sticking coefficient, which accounts for the fraction of the number of impinging molecules that is retained on the surface, varies with gas species, temperature of the surface and molecule, and surface coverage; it is indirectly related to the accommodation coefficient for heat transfer, which in terms of energy and temperature is (References 2 and 14)

$$
\alpha_{s}=\frac{E-E_{g}}{E_{s}-E_{g}}=\frac{T-T_{g}}{T_{s}-T_{g}} \quad \text { for } T_{s}>T_{g},
$$

where the subscript $s$ stands for surface, $g$ stands for gas, and no subscript stands for the reflected gas molecule. For most gas/solid combinations, $0.1<\gamma<1.0$ (Reference 2). Figure 7, taken from Reference 15, shows $\alpha_{s}$ for various gases on platinum and on a few other materials as a function of the gas temperature. The figure is a compilation of experimental results obtained by various authors. The general feature of these curves, besides the dependence on temperature, is that light atoms and molecules tend to have lower values of $\alpha_{s}$. The sticking coefficient appears to show the same general features; it declines when monolayer coverage is approached.

The average time a molecule stays on the surface before it evaporates (residence time) may be estimated by

$$
\tau=\tau_{0} \exp (Q / R T)
$$

where $\tau_{0}$ is the period of oscillation of the adsorbed molecule perpendicular to the surface. It is related to the lattice vibration of the solid surface and has a value of $10^{-12}$ to $10^{-14} \mathrm{~s}$. The term $T$ is the absolute temperature of the surface, $Q$ is the heat of adsorption of the gas, and $R$ is the gas constant. The heat of adsorption is controlled by the molecular weight, molecular shape, and details of the surface. Water vapor has a theoretical energy of physical adsorption near its latent heat of vaporization $\left(10.7 \times 10^{3} \mathrm{cal} / \mathrm{mole}\right)$. Some experimental results have indicated the value to be between $10 \times 10^{3}$ and $15 \times 10^{3} \mathrm{cal} / \mathrm{mole}$ (Reference 16). Table 1 gives the residence times $\tau$ calculated for $\tau_{0}=10^{-13} \mathrm{~s}$ and various temperatures and heats of adsorption. A single value is also reported for $\mathrm{H}, \mathrm{N}$, light organic materials, and pump oils at room temperature. In conclusion, for this type of surface phenomenon, the number of molecules per unit surface area which may be adsorbed on a spacecraft surface is given by Equation 39, with the substitution of Equation 34 for the flux and Equation 41 for $\tau$, i.e.,

$$
\left.\sigma=\frac{\gamma N_{D}\left(1+\frac{v_{0}}{v_{D}}\right)}{4 \pi R \lambda_{0}} \tau_{0} \exp (Q / R T) \quad \text { (molecules-cm }{ }^{-2}\right)
$$

The relation shows that the molecular coverage (1) is a direct function of the outgassing $N_{D} ;(2)$ decreases with increasing spacecraft radius and altitude; and (3) decreases with the surface temperature and increases with the heat of adsorption, both of these in an exponential fashion. 
Table $1-$ Residence time of molecules on a surface $\left[\tau=10^{-13} \exp (Q / R T)\right.$ (in seconds) $]$ for various temperatures and heats of adsorption.

\begin{tabular}{|c|c|c|c|c|c|c|c|c|}
\hline \multirow{2}{*}{$\begin{array}{c}\text { Heat of } \\
\text { Adsorption } Q \\
\text { (cal } / \text { mole) }\end{array}$} & \multicolumn{7}{|c|}{$\begin{array}{l}\text { Temperature } T \\
(K)\end{array}$} & \multirow{2}{*}{ Notes* } \\
\hline & $\begin{array}{c}73 \\
\left(-200^{\circ} \mathrm{C}\right)\end{array}$ & $\begin{array}{c}173 \\
\left(-100^{\circ} \mathrm{C}\right)\end{array}$ & $\begin{array}{c}253 \\
\left(-20^{\circ} \mathrm{C}\right)\end{array}$ & $\begin{array}{c}273 \\
\left(0^{\circ} \mathrm{C}\right)\end{array}$ & $\begin{array}{c}293 \\
\left(20^{\circ} \mathrm{C}\right)\end{array}$ & $\begin{array}{c}373 \\
\left(100^{\circ} \mathrm{C}\right)\end{array}$ & $\begin{array}{c}773 \\
\left(500^{\circ} \mathrm{C}\right)\end{array}$ & \\
\hline \multirow[t]{2}{*}{100} & $1.9 \times 10^{-13}$ & $1.4 \times 10^{-13}$ & $1.2 \times 10^{-13}$ & $1.2 \times 10^{-13}$ & $1.2 \times 10^{-13}$ & $1.2 \times 10^{-13}$ & & \multirow{10}{*}{$\begin{array}{l}\mathrm{H}_{2} \mathrm{O} \text { : minimum } \\
\text { heat of } \\
\text { adsorption } \\
\mathrm{H}_{2} \mathrm{O} \text { : maximum } \\
\text { heat of } \\
\text { adsorption }\end{array}$} \\
\hline & & & & & $1.0 \times 10^{-12}$ & & & \\
\hline 1500 & $2.2 \times 10^{-9}$ & $1.5 \times 10^{-11}$ & $1.9 \times 10^{-12}$ & $1.6 \times 10^{-12}$ & $1.2 \times 10^{-12}$ & $1 \times 10^{-12}$ & & \\
\hline 3500 & $1.2 \times 10^{-7}$ & $1.63 \times 10^{-8}$ & $1.0 \times 10^{-10}$ & $6.3 \times 10^{-11}$ & $4 \times 10^{-11}$ & $2.4 \times 10^{-11}$ & $1 \times 10^{-12}$ & \\
\hline 4000 & $3.5 \times 10^{-3}$ & $1.0 \times 10^{-7}$ & $2.8 \times 10^{-10}$ & $1.6 \times 10^{-10}$ & $1 \times 10^{-10}$ & $5.5 \times 10^{-11}$ & $1.5 \times 10^{-12}$ & \\
\hline 10000 & $7.3 \times 10^{15}$ & $2.7 \times 10^{1}$ & $4 \times 10^{-5}$ & $1.0 \times 10^{-5}$ & $3 \times 10^{-6}$ & $7.2 \times 10^{-7}$ & $7 \times 10^{-11}$ & \\
\hline 15000 & \multirow{4}{*}{$5.3 \times 10^{44}$} & \multirow{4}{*}{$7.3 \times 10^{15}$} & & & $1.7 \times 10^{-2}$ & & & \\
\hline 20000 & & & $1 \times 10^{4}$ & $1.0 \times 10^{3}$ & $1 \times 10^{2}$ & 5 & $5 \times 10^{-8}$ & \\
\hline 30000 & & & $8 \times 10^{12}$ & $1.0 \times 10^{11}$ & $4 \times 10^{9}$ & $4.3 \times 10^{7}$ & $4 \times 10^{-5}$ & \\
\hline 40000 & & & $3.6 \times 10^{21}$ & $1.0 \times 10^{19}$ & $1 \times 10^{17}$ & $2.6 \times 10^{14}$ & $3 \times 10^{-2}$ & \\
\hline
\end{tabular}

*From Reference 16: Pump oils at $\nu=10^{4} \mathrm{~cm}-\mathrm{s}^{-1}, \tau=10^{2} \mathrm{~s}$ (but questionable for these large molecules). Light-organic substance at $\nu=10^{4} \mathrm{~cm}-\mathrm{s}^{-1}, \tau=10^{-4} \mathrm{~s}$.

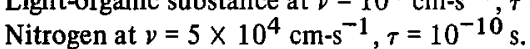




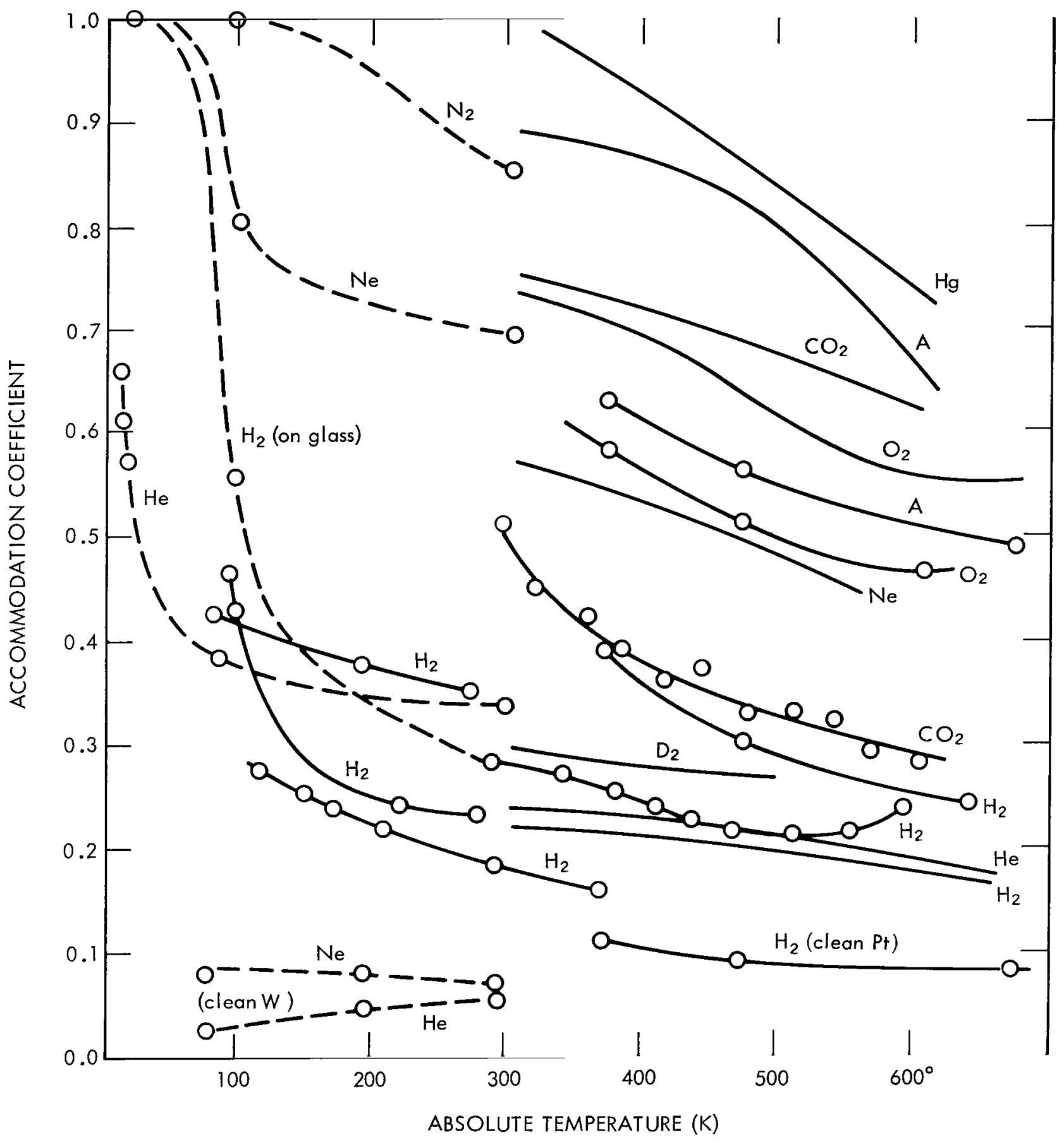

Figure 7-Accommodation coefficients of various gases on platinum (except as noted) vs. absolute temperature. 


\section{Contaminant Condensation}

For condensation to occur, the partial pressure of the contaminant $P^{\prime \prime}$ (Equation 32) must be higher than the saturated vapor pressure $P_{s}$ of the contaminant corresponding to the temperature $T_{s}$ of the surface. The saturation pressure is given by the Clapeyron relation, $\log P_{s}=A-B / T_{s}$, where $A$ and $B$ are constants for each gas. The rate of condensation is then given by the difference between the impinging flux (in our case $\phi^{\prime \prime}$ ) and the evaporation flux $\phi_{s}$ dictated by the saturation pressure $P_{s}$, i.e.,

$$
\begin{aligned}
\nu & =\alpha\left(\phi^{\prime \prime}-\phi_{s}\right)=\alpha \phi^{\prime \prime}\left(1-\frac{\phi_{s}}{\phi^{\prime \prime}}\right) \\
& =\alpha \phi^{\prime \prime}\left(1-\frac{P_{s}}{P^{\prime \prime}} \sqrt{\frac{T^{\prime \prime}}{T_{s}}}\right),
\end{aligned}
$$

where $\alpha$ is the coefficient of condensation relating the temperatures of the gas and condensed phases. If

$$
\frac{P_{s}}{P^{\prime \prime}} \sqrt{\frac{T^{\prime \prime}}{T_{s}}} \ll 1,
$$

occurring when $P_{s}$ is an order of magnitude or more lower than $P^{\prime \prime}$, we can disregard the evaporation part, and the condensation rate is simply

$$
\nu=\alpha \phi^{\prime \prime}=\frac{\alpha N_{D}\left(1+\frac{v_{0}}{v_{D}}\right)}{4 \pi R \lambda_{0}} \quad \text { (molecules-cm }{ }^{-2}-\mathrm{s}^{-1} \text { ). }
$$

The coefficient $\alpha$ is generally taken as unity in this case. We conclude that the rate of gas molecule accumulation decreases with altitude and size of spacecraft and is a direct function of the outgassing.

\section{NUMERICAL CALCULATIONS}

Application of the equations allows us to calculate the pressure, density, and the mean free path of the gas ahead of the moving spacecraft. Further, a knowledge of the spacecraft outgassing permits us to estimate the adsorption isotherm, the mass column density, and the rate at which outgassing contaminants impinge on the spacecraft surface. These calculations have been carried for a number of spacecraft, and the results are shown in Tables 2 and 3. The selection of these spacecraft for analysis was dictated merely by the availability of outgassing data. Reference 12 reports experimental data on the gas leakage of the Gemini 3, Gemini 11, Apollo, and ATM in addition to the altitude and equivalent radius of each spacecraft. For the others, outgassing was estimated from available space-chamber thermal-vacuum test data not intended for the evaluation of this parameter. The estimation was performed using the method of conductance, which consists of the comparison of the pumpdown curves of the chamber with and without the spacecraft, and the use of the chamber pumping speed for a particular gas. The results of these calculations indicate order of magnitude for the outgassing and are not fully representative of their outgassing. In fact, they do not include the effects of solar paddles 
Table 2-Satellite parameters.

\begin{tabular}{|c|c|c|c|c|c|c|c|c|c|c|}
\hline \multirow[b]{3}{*}{ Satellite } & \multicolumn{10}{|c|}{ Parameter } \\
\hline & \multirow{2}{*}{$\begin{array}{l}\text { Satellite } \\
\text { Radius } R_{E} \\
\quad \text { (cm) }\end{array}$} & \multirow{2}{*}{$\begin{array}{l}\text { Altitude } h \\
\quad(\mathrm{~km})\end{array}$} & \multirow{2}{*}{$\begin{array}{l}\text { Neutral } \\
\text { Concen- } \\
\text { tration } n_{0} \\
\left(\mathrm{~cm}^{-3}\right)\end{array}$} & \multirow{2}{*}{$\begin{array}{c}\text { Pressure } \\
P_{0} \\
\text { (torr) }\end{array}$} & \multirow{2}{*}{$\begin{array}{c}\text { Mean Free } \\
\text { Path } \lambda_{0} \\
(\mathrm{~cm})\end{array}$} & \multicolumn{3}{|c|}{ Outgassing (Given/Calculated) } & \multirow{2}{*}{$\begin{array}{l}\text { Molecular } \\
\text { Mass } M \\
\text { (g) }\end{array}$} & \multirow{2}{*}{$\begin{array}{c}\text { Temper- } \\
\text { ature } T \\
(\mathrm{~K})\end{array}$} \\
\hline & & & & & & $\underset{\left(\text { torr }-1-\mathrm{s}^{-1}\right)}{Q}$ & $\underset{\left(g-s^{-1}\right)}{\dot{m}}$ & $\begin{array}{c}\dot{N} \\
\text { (molecules-s }^{-1} \text { ) }\end{array}$ & & \\
\hline Gemini 3 & 200 & 160 & $5.24 \times 10^{10}$ & $4.13 \times 10^{-6}$ & $2.5 \times 10^{3}$ & $4.3 \times 10^{0}$ & $4.2 \times 10^{-3}$ & $1.42 \times 10^{20}$ & 18 & 293 \\
\hline Gemini 2 & 200 & 300 & $1.72 \times 10^{9}$ & $1.95 \times 10^{-7}$ & $1 \times 10^{5}$ & $1.43 \times 10^{1}$ & $1.4 \times 10^{-2}$ & $4.74 \times 10^{20}$ & 18 & 293 \\
\hline Apollo & 200 & 300 & $1.72 \times 10^{9}$ & $1.95 \times 10^{-7}$ & $1 \times 10^{5}$ & $3.06 \times 10^{1}$ & $3 \times 10^{-2}$ & $1.01 \times 10^{21}$ & 18 & 293 \\
\hline ATM & 300 & 400 & $3.48 \times 10^{8}$ & $3.98 \times 10^{-8}$ & $1 \times 10^{6}$ & $1.02 \times 10^{2}$ & $1 \times 10^{-1}$ & $3.3 \times 10^{21}$ & 18 & 293 \\
\hline IMP 2 & $\sim 50$ & 200 & $1.5 \times 10^{10}$ & $1.35 \times 10^{-6}$ & $8 \times 10^{3}$ & $2 \times 10^{0}$ & $2 \times 10^{-3}$ & $6.6 \times 10^{19}$ & 18 & 293 \\
\hline ISIS 1 & $\sim 55$ & 575 & $4 \times 10^{7}$ & $4 \times 10^{-9}$ & $1 \times 10^{7}$ & $9 \times 10^{-1}$ & $9 \times 10^{-4}$ & $3 \times 10^{19}$ & 18 & 293 \\
\hline Nimbus (FWS) & $\sim 70$ & 1100 & $9.45 \times 10^{5}$ & $1.08 \times 10^{-10}$ & $1 \times 10^{9}$ & $8.9 \times 10^{-3}$ & $8.9 \times 10^{-6}$ & $2.8 \times 10^{17}$ & 18 & 293 \\
\hline Source & given & given & Ref. 1 & Ref. 1 & Ref. 1 & $\begin{array}{c}\text { Eq. } 1 \\
\text { or given }\end{array}$ & $\begin{array}{c}\text { Eq. } 3 \\
\text { or given }\end{array}$ & $\begin{array}{c}\text { Eq. } 2 \\
\text { or given }\end{array}$ & assumed & given \\
\hline
\end{tabular}


Table 3-Calculation.

\begin{tabular}{|c|c|c|c|c|c|c|c|c|c|c|c|c|c|c|}
\hline \multirow{3}{*}{ Satellite } & \multicolumn{14}{|c|}{ Parameter } \\
\hline & \multicolumn{2}{|c|}{$\begin{array}{l}\text { Mean Free } \\
\text { Path }(\mathrm{cm})\end{array}$} & \multicolumn{3}{|c|}{$\begin{array}{l}\text { Molecular Concentration } \\
\qquad\left(\mathrm{cm}^{-3}\right)\end{array}$} & \multicolumn{2}{|c|}{$\begin{array}{l}\text { Pressure } \\
\text { (torr) }\end{array}$} & \multirow{2}{*}{$\begin{array}{c}\text { Reverse } \\
\text { Pressure } P^{\prime \prime} \\
\text { (torr) }\end{array}$} & \multicolumn{2}{|c|}{$\underset{\left(\mathrm{cm}^{-2} \cdot \mathrm{s}^{-1}\right)}{\text { Flux }}$} & \multirow{2}{*}{$\begin{array}{c}\text { Adsorption } \sigma \\
\left(\mathrm{cm}^{-2}\right)\end{array}$} & \multirow{2}{*}{$\begin{array}{c}\text { Condensation } \\
\text { Rate } \nu \\
\left(\mathrm{cm}^{-2}-\mathrm{s}^{-1}\right)\end{array}$} & \multirow{2}{*}{$\begin{array}{l}\text { Time to } \\
\text { Form a } \\
\text { Monolayer* } \\
t \\
\text { (s) }\end{array}$} & \multirow{2}{*}{$\begin{array}{c}\text { Mass } \\
\text { Column } \\
\text { Density } \\
M_{s} \\
\left(\mathrm{gm}-\mathrm{cm}^{-2}\right)\end{array}$} \\
\hline & $\begin{array}{c}\text { Desorbed } \\
\lambda_{D} \\
\end{array}$ & \begin{tabular}{|c|c} 
Reflected \\
$\lambda_{R}$
\end{tabular} & $\begin{array}{c}\text { Reflected } \\
n_{R}\end{array}$ & $\begin{array}{c}\text { Desorbed } \\
n_{D} \\
\end{array}$ & $\begin{array}{c}\text { Reverse } \\
n^{\prime \prime} \\
\end{array}$ & $\begin{array}{l}\text { Reflected } \\
P_{R} \\
\end{array}$ & $\begin{array}{c}\text { Desorbed } \\
P_{D} \\
\end{array}$ & & $\begin{array}{c}\text { Desorbed } \\
\phi_{D} \\
\end{array}$ & $\begin{array}{c}\text { Reverse } \\
\phi^{\prime \prime}\end{array}$ & & & & \\
\hline Gemini 3 & $\approx 1.0 \times 10^{2}$ & $6 \times 10^{2}$ & $7.95 \times 10^{10}$ & $7.1 \times 10^{9}$ & $\approx 4.9 \times 10^{8}$ & $6.22 \times 10^{-6}$ & $2.15 \times 10^{-7}$ & $\approx 1.5 \times 10^{-8}$ & $2.83 \times 10^{14}$ & $\approx 1.96 \times 10^{14}$ & $\approx 1.96 \times 10^{10}$ & $1.96 \times 10^{14}$ & 2.68 & $2 \times 10^{-12}$ \\
\hline Gemini 2 & $5 \times 10^{3}$ & $3.5 \times 10^{4}$ & $2.6 \times 10^{9}$ & $2.83 \times 10^{10}$ & $1.13 \times 10^{8}$ & $2.94 \times 10^{-7}$ & $8.65 \times 10^{-7}$ & $3.45 \times 10^{-9}$ & $1.13 \times 10^{15}$ & $4.5 \times 10^{13}$ & $4.5 \times 10^{9}$ & $4.5 \times 10^{13}$ & 11.6 & $6.9 \times 10^{-12}$ \\
\hline Apollo & $5 \times 10^{3}$ & $3.5 \times 10^{4}$ & $2.6 \times 10^{9}$ & $6 \times 10^{10}$ & $2.9 \times 10^{8}$ & $2.94 \times 10^{-7}$ & $1.84 \times 10^{-7}$ & $6.12 \times 10^{-9}$ & $2.4 \times 10^{15}$ & $9.6 \times 10^{13}$ & $9.6 \times 10^{9}$ & $9.6 \times 10^{13}$ & 5.5 & $1.4 \times 10^{-11}$ \\
\hline ATM & $4.5 \times 10^{4}$ & $3 \times 10^{5}$ & $5.25 \times 10^{8}$ & $2.3 \times 10^{11}$ & $1.71 \times 10^{8}$ & $6 \times 10^{-8}$ & $7.14 \times 10^{-6}$ & $5.32 \times 10^{-9}$ & $9.25 \times 10^{15}$ & $5.5 \times 10^{13}$ & $5.5 \times 10^{9}$ & $5.5 \times 10^{13}$ & 9.6 & $3.2 \times 10^{-11}$ \\
\hline IMP 2 & $4 \times 10^{2}$ & $2 \times 10^{3}$ & $2.25 \times 10^{10}$ & $5.26 \times 10^{10}$ & $6.6 \times 10^{8}$ & $2.03 \times 10^{-6}$ & $1.6 \times 10^{-6}$ & $2 \times 10^{-8}$ & $2.1 \times 10^{15}$ & $2.3 \times 10^{14}$ & $2.3 \times 10^{10}$ & $2.3 \times 10^{14}$ & 2.28 & $3.9 \times 10^{-12}$ \\
\hline ISIS 1 & $5.5 \times 10^{5}$ & $4 \times 10^{6}$ & $6 \times 10^{7}$ & $2.4 \times 10^{10}$ & $1.55 \times 10^{5}$ & $6 \times 10^{-9}$ & $7.2 \times 10^{-7}$ & $4.66 \times 10^{-13}$ & $9.7 \times 10^{14}$ & $5.8 \times 10^{10}$ & $5.8 \times 10^{6}$ & $5.8 \times 10^{10}$ & $9.15 \times 10^{3}$ & $1.6 \times 10^{-12}$ \\
\hline Nimbus & $6.5 \times 10^{7}$ & $4 \times 10^{8}$ & $1.4 \times 10^{6}$ & $1.68 \times 10^{8}$ & $1.6 \times 10^{1}$ & $1.62 \times 10^{-10}$ & $5.3 \times 10^{-9}$ & $5.3 \times 10^{-16}$ & $6.75 \times 10^{12}$ & $1.68 \times 10^{7}$ & $1.68 \times 10^{3}$ & $P^{\prime \prime}<P$ & $3.12 \times 10^{17}$ & $1.3 \times 10^{-14}$ \\
\hline $\begin{array}{l}\text { Equation } \\
\text { or curve }\end{array}$ & $\begin{array}{l}\text { Eq. } 8 \\
\text { Fig. } 1\end{array}$ & $\begin{array}{l}\text { Eq. } 11 \\
\text { Fig. } 1\end{array}$ & $\begin{array}{l}\text { Eq. } 31 \\
\text { Fig. } 3\end{array}$ & $\begin{array}{l}\text { Eq. } 28 \\
\text { Fig. } 2\end{array}$ & $\begin{array}{l}\text { Eys } 32.33 \\
\text { Fygs } 4.5\end{array}$ & $\begin{array}{l}\text { Eq. } 31 \\
\text { Fig. } 3\end{array}$ & $\begin{array}{r}\text { Eq. } 29 \\
\text { Fig. } 2\end{array}$ & \begin{tabular}{|c} 
Eqs 32.33 \\
Figs \\
4.5
\end{tabular} & $\begin{array}{l}\text { Eq. } 30 \\
\text { Fig. } 5\end{array}$ & $\begin{array}{c}\text { Eqs } 34.35 \\
\text { Fig. } 4\end{array}$ & Eq. 42 & Eq. 43 & & Eq. 37 \\
\hline
\end{tabular}

*A monolayer of $\mathrm{H}_{2} \mathrm{O}, 5.27 \times 10^{14}$ molecules $-\mathrm{cm}^{-2}$. 
(IMP B). The Nimbus outgassing includes only a fraction of the total. The amount used for the calculation was obtained analytically for the filter wedge spectrometer experiment package.* The inclusion of this is of interest because of the recent investigation on the causes of "icing" of the detector of this experiment and because of the questions raised during this investigation about possible external source of contamination.* The orbital altitudes used for the determination of the space parameters of the IMP and ISIS are those at the perigee. The equivalent radii of these spacecraft have been estimated from their dimensions.

In addition to the above, the following assumptions have been made for the calculations:

(1) The spacecraft are represented by a sphere of given radius.

(2) The thermal energy of the outgassing molecules is such that their average velocity is $0.4 \mathrm{~km}-\mathrm{s}^{-1}$, corresponding to a temperature of about $293 \mathrm{~K}\left(20^{\circ} \mathrm{C}\right)$.

(3) The outgassing emanates uniformly from the sphere and in amounts such that the molecules, in general, do not collide with each other. Their trajectories are straight until they collide with the ambient molecules.

(4) The contamination results from the flux of ambient reflected molecules and not from direct impingement of outgassed molecules.

(5) The sticking coefficient $\gamma$ for the adsorption is taken as unity. As indicated previously, this coefficient varies between 0.1 and 1 , but the choice of unity will yield conservative results for the adsorption.

(6) Residence time $\tau$ has been taken as $10^{-4} \mathrm{~s}$. This conservative choice is based on the facts that (1) as indicated by Reference 16 and shown in Table 1, water vapor may have a heat of adsorption such that its residence time at $293 \mathrm{~K}\left(20^{\circ} \mathrm{C}\right)$ is $1.7 \times 10^{-2} \mathrm{~s}$; (2) pump oils may have a value of $10^{2} \mathrm{~s}$ at this temperature; and (3) light organic materials representative of some of the expected spacecraft outgassing materials (e.g., aliphatic hydrocarbons, aromatic esters, and silicone) have residence times of $10^{-4} \mathrm{~s}$.

(7) The condensation rate coefficient $\alpha$ has been taken as unity (according to the discussion of this topic).

(8) The condensation rate is not slowed by evaporation, i.e., it is assumed that $P_{S} \ll P^{\prime \prime}$.

(9) The velocity of the returning molecules $v_{n}$ has been taken as one-half the spacecraft velocity $\left(\approx 4 \mathrm{~km}-\mathrm{s}^{-1}\right)$, for the reasons given under the discussion of this subject. This value is necessary for the estimation of $P^{\prime \prime}$.

(10) The outgassing value of the GSFC satellites is that estimated to occur during the first hour and for a spacecraft at ambient temperature. The value decreases with time according to one of the

\footnotetext{
*"Report of Findings of the Radiation Cooler Task Group", NASA-GSFC T\&E DIRS No. 02273-I-2-TR239032-215, Sept. 1970.
} 
laws discussed under "Contamination Sources-Outgassing." It is understood that for these spacecraft, the values obtained for contamination are for the first hour only. Values for later times can be estimated by reducing the given values in direct proportion to the time elapsed. The outgassing for Gemini, Apollo, and ATM are continuous and constant with time, as indicated in Reference 14.

Given in Table 3 are the numbers of the equations and figures used in conjunction with the parameters of Table 2 to obtain the calculated values.

\section{CONCLUSION AND SUMMARY}

The contamination from the environment surrounding a spacecraft in orbit can be estimated if the spacecraft outgassing rate is available from tests or calculations.

Outgassing depends on the quantity and nature of onboard materials, their temperatures, and the duration of exposure to vacuum conditions.

In space, a part of the outgassing flux diffusing away from the spacecraft returns to the spacecraft. The returning amount varies from about 50 percent of the total outgassing at 160 to $170 \mathrm{~km}$, down to one-millionth or less of the total at $1000 \mathrm{~km}$ and higher. The decrease results from the less frequent collision of the outgassed molecules with ambient molecules. The collision is dictated by the desorbed molecules' mean free path, which is less than that of the ambient molecules.

The returning outgassed flux may retard the complete outgassing of the surfaces, form adsorption monolayers on nonoutgassing surfaces, or condense at a given rate on a cold surface. It is estimated that for normal surface temperatures and chemical natures of the outgassed molecules, the number of molecules adsorbed on a clean surface is less than $1 / 100$ of the flux of the returning molecules $\left(\tau=10^{-4}\right.$ was used for calculations). This may amount to a few monolayers. The condensation rate on a sufficiently cold surface is about the same of the returning molecule flux. Based on outgassing rates calculated by the author or given in the literature, contamination values and other parameters have been calculated for a number of spacecraft. The following examples, taken from those in Tables 2 and 3, indicate the magnitude of the contamination rates.

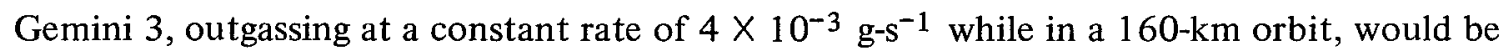
exposed to a contaminant flux of about $1.9 \times 10^{14}$ molecules- $\mathrm{cm}^{-2}-\mathrm{s}^{-1}$. Under noncondensing conditions, this would produce an adsorption of $1.9 \times 10^{10}$ molecules-cm ${ }^{-2}$ (i.e., less than a monolayer).

The ATM, with a constant outgassing rate of $0.1 \mathrm{~g}-\mathrm{s}^{-1}$ and at a $400-\mathrm{km}$ altitude, would be exposed to a return flux of $5.5 \times 10^{13}$ molecules- $\mathrm{cm}^{-2}-\mathrm{s}^{-1}$. The adsorption would be $5.5 \times 10^{9}$ molecules- $\mathrm{cm}^{-2}$.

IMP 2, with an estimated initial (first-hour) outgassing rate of $2 \times 10^{-3} \mathrm{~g}-\mathrm{s}^{-1}$ and at the perigee altitude of $200 \mathrm{~km}$, would have a return flux and condensation rate of $2.3 \times 10^{14}$ and an adsorption of $2.3 \times 10^{10}$ molecules- $\mathrm{cm}^{-2}$.

In the process of establishing these fluxes, the environment around an orbiting spacecraft was analyzed. The electric potential acquired by the spacecraft was also investigated, and it appears to 
have little effect on the molecular flow of the outgassed material. A brief description of the environment surrounding the spacecraft follows.

In the frontal region of the spacecraft-

(1) The mean free path of the molecules leaving the spacecraft is less than that of the ambient molecules. For near-earth-orbit velocities and normal surface temperatures, the mean free path is about one-twentieth of that of the ambient molecules.

(2) The density at the spacecraft surface is 2.5 to 3 times that of the environment. The drop of these parameters with the distance from the spacecraft is less at higher than at lower altitudes. It is also less for small satellites than for large ones. At altitudes greater than $200 \mathrm{~km}$, the values of these parameters approach those of the environment at about 2 spacecraft radii from its surface.

(3) At $2 \mathrm{~m}$ from the surface, the density or pressure produced by the outgassing becomes onetenth the value at the surface at $200 \mathrm{~km}$ or higher. At lower altitudes $(\approx 100 \mathrm{~km})$, the same reduction is produced within $10 \mathrm{~cm}$ from the surface.

(4) At the spacecraft surface, the ratio of the outgassed molecules returning to the spacecraft to the total outgassed molecules varies from about 60 percent at $160 \mathrm{~km}$ to $10^{-6}$ to $10^{-7}$ at $1000 \mathrm{~km}$. Ninety percent of these returning molecules result from collisions with other molecules within $2 \mathrm{~m}$ of the spacecraft. At higher altitudes, the same may occur within $3 \mathrm{~m}$.

A rarefied region forms behind a moving spacecraft. Ambient conditions are reestablished at a distance of about 25 times the spacecraft radius. Outgassed material emitted in this region should not return to the spacecraft.

Goddard Space Flight Center

National Aeronautics and Space Administration

Greenbelt, Maryland, August 24, 1971

114-03-58-01-51

\section{REFERENCES}

1. U. S. Standard Atmosphere, 1962, U. S. Government Printing Office, Washington, D. C., 1966.

2. Handbook of Thin Film Technology, L. I. Maissel and R. Glang, eds., McGraw-Hill Book Co., New York, 1970.

3. Santeler, D., et al., "Vacuum Technology and Space Simulation", NASA SP-105, 1966.

4. Dayton, B. B., "Relations Between Size of Vacuum Chamber, Outgassing Rate, and Required Pumping Speed", 6th National Symposium on Vacuum Technology Trans., Pergamon Press, New York, 1959. 
5. Muraca, R. F., and Whittick, J. S., "Polymers for Spacecraft Applications", JPL Contract No. 950745 (Under NAS7-100), Stanford Research Institute, U. S. Department of Commerce Report No. N67 40270.

6. Mirtov, B. A., "Disturbances of Gaseous Medium Caused by Satellite Flight", Annals of IGY, 1957 to 1958.

7. Alpert, E. L., Gurevic, A. V., and Pitaevskij, L. P., “On the Effects Produced by a Fast-Moving Body in a Plasma", Proceedings of the 3rd International Space Science Meeting, Washington, D. C., May 1962.

8. Kurt, P. G., and Moroz, V. I., "The Potential of a Metal Sphere in Interplanetary Space", Planet. Space Sci. 9, 1962.

9. Brundin, C. L., "Effects of Charged Particles on the Motion of an Earth Satellite", $A I A A$ Journal 1(11), November 1963.

10. Chopra, K. P., "Interactions of Rapidly Moving Bodies in Terrestrial Atmosphere", Rev. Modern Phys. 33, April 2, 1961.

11. Alpert, E. L., Gurevic, A. V., and Pitaevskij, L. P., "Effects Due to an Artificial Earth Satellite in Rapid Motion Through the Ionosphere or the Interplanetary Medium", Space Sci. Rev. 2, 1963.

12. Kovar, N. S., Kovar, R. P., and Bonner, G. P., "Light Scattering by Manned Spacecraft Atmosphere", Planet. Space Sci. 17, 1969.

13. Newkirk, G., "The Optical Environment of Manned Spacecraft", Planet. Space Sci. 15, 1967.

14. Wachman, H. Y., "The Thermal Accommodation Coefficient: A Critical Survey", ARS Journal, January 1962.

15. Thomas, L. B., "Thermal Accommodation of Gases on Solids", in Fundamentals of Gas-Surface Interactions, H. Saltsburg et al., eds., Academic Press, New York, 1967, p. 346.

16. Hayashi, C., "Role of Adsorption in Production and Measurement of High Vacuum", Vacuum Symposium Trans., Pergamon Press, New York, 1957. 


\section{UNCITED REFERENCES}

Dushman, S., Scientific Foundations of Vacuum Techniques, J. M. Lafferty, ed., J. Wiley and Sons, New York, 1962.

McPherson, D. G., "ATM Contamination Study", Contract NASW 1386, Ball Brothers Research Corp. 1967.

Schamberg, R., "Analytic Representation of Surface Interaction for Free Molecule Flow with Application to Drag of Various Bodies", Aerodynamics of Upper Atmosphere, Masson, ed., Rand Corp., 1959.

Scialdone, J. J., "Internal Pressures of a Spacecraft or Other System of Compartments, Connected in Various Ways and Including Outgassing Materials in a Time Varying Pressure Environment", NASA-GSFC Document X-327-69-524, August 1969. 


\section{APPENDIX \\ Electric Field Considerations}

Calculations in text have been based on the behavior of neutral particles. It may happen that when the spacecraft acquires an electric potential sufficient to create an appreciable electrostatic field, some molecules may acquire electrical polarity or become ionized if they experience a collision with high-energy particles. In these cases, the gas kinetic equation must include electric and magnetic forces. The parameters that affect the spacecraft potential will be reviewed briefly (References 7 through 11), and it will be shown that the electrostatic force will not significantly disturb the motion of the molecule.

The potential of a metallic spacecraft in a plasma is determined by the balance of the electric currents produced by the collision with charged particles and by the emission, caused by surface irradiation, of electrons. These currents are $I_{e}$, the current produced by the absorption of plasma electrons; $I_{r e}$, the current produced by the absorption of electrons in passing through the radiation belts; $I_{i}$, the current produced by the plasma ions; $I_{r p}$, the cu rent produced by protons; $I_{p h}$, the current of photoelectron emission caused by shortwave solar radiation; and $I_{s}$, a secondary current produced under bombardment of the spacecraft by high-energy particles. The potential is then

$$
\phi(t)=\frac{1}{C} \int_{0}^{t} \Sigma I d t+\phi(0),
$$

where $C$ is the capacitance of the spacecraft.

At altitudes above the ionosphere (i.e., $>1000 \mathrm{~km}$ ), the $I_{p h}$ current is substantial. It is determined by the flux of photoelectrons per unit area yielded by the material under the solar radiant flux.: The spacecraft then assumes a positive potential which increases with time; but the increase will be slowed by the negative charges which form around the spacecraft. These charges will provide a shield against further electron loss.

At altitudes corresponding to the radiation belts (i.e., between 0.5 and 3 earth radii), the current $I_{r e}$ produced by the radiation electrons is appreciably larger than $I_{r p}$, the current produced by the protons, because in a plasma having equal number of electrons and protons, the flux of electrons will be larger than that of the protons due to their different velocities. That is,

$$
\frac{n_{e} v_{e}}{4} \gg \frac{n_{p} v_{p}}{4} .
$$

It is also true that $n_{e}>n_{p}$ in the radiation belts. Hence, $I_{r p}$ can be neglected in comparison with $I_{r e}$, which will be quite large at the top of the radiation belts. In fact, there it will exceed the photoelectron current, and the spacecraft may acquire a negative potential. The secondary emission current $I_{s}$ under the influence of $I_{r e}$ tends to increase the potential. 
In the ionosphere $(<1000 \mathrm{~km}), I_{i}$ and $I_{e}$, produced by collision of the spacecraft with the ambient plasma, are most intense. The ion current can be approximated by

$$
I_{i}=\pi R^{2} v_{0} n_{i} e,
$$

where $n_{i}$ is the ambient ion concentration, $v_{0}$ is the velocity of the spacecraft, and $R$ is its radius. The electron current, which is dependent on the existing spacecraft potential, is approximated by

$$
I_{e}=\frac{\pi R^{2}}{2} e \nu_{e} n_{e} \exp \frac{-\phi_{0} e}{K T}
$$

where $n_{e}$ is the electron concentration and $v_{e}$ is the mean electron velocity. Assuming no photoelectron or radiation particle current, a spacecraft passing through a plasma with $n_{e}=n_{i}$ will acquire the potential (Reference 8)

$$
\begin{aligned}
\phi_{0} & =\frac{K T}{e} \ln \frac{\nu_{e}}{2 v_{0}} \\
& \approx \frac{K T}{e} \ln \sqrt{\frac{2 K T}{\pi m_{e} \nu_{0}^{2}}},
\end{aligned}
$$

obtained by equating the two currents $I_{e}$ and $I_{i}$. This is a negative potential, about 2 to 3 times $K T / e$, the thermal plasma potential (which, for $T<10^{4} \mathrm{~K}$, is a few volts).

The general equation of current balance has been solved graphically for values of $n_{i}, T, v$, and so forth, that are possible in the upper atmosphere and in interplanetary space. A potential of about $-20 \mathrm{~V}$ is obtained for a 65 -cm-radius spacecraft if $T \approx 10^{3}$ to $10^{4} \mathrm{~K}$ and $n_{i}=10^{3} \mathrm{~cm}^{-3}$. A potential of -5 to $-3 \mathrm{~V}$ results for the same conditions except for $n_{i}$ being set to $10^{5} \mathrm{~cm}^{-3}$. Outside the radiation belts, a spacecraft under illumination would acquire a potential between -2.5 and $+4 \mathrm{~V}$. In addition to the above, the magnetic field, the radio-frequency field, and other minor effects must be considered. At high altitudes, the magnetic field is not important, because the Larmor radii of the particles at those altitudes exceed the spacecraft radius. At lower altitudes $(<7000 \mathrm{~km})$, where the Larmor radii are less than or equal to the spacecraft radius, the electron current is reduced by one-half because of the magnetic field, and the potential approaches zero.

\section{Ionized Desorbed Molecules}

Some of the molecules desorbed by the spacecraft may be ionized by collision with high-energy particles. References 6 and 7 indicate that a coefficient of ionization $\beta=10^{-4}$ can be used to establish the fraction of desorbed molecules that may become so ionized. Therefore, the ionized fraction of the flux may be

$$
\begin{aligned}
\phi_{i} & =\beta \phi^{\prime \prime} \\
& =10^{-4} N_{D} \frac{1+\frac{v_{0}}{v_{D}}}{4 \pi R \lambda_{0}} .
\end{aligned}
$$


For $h=1000 \mathrm{~km}, \phi^{\prime \prime}=10^{-12} N_{D}$, as given by Figure 4. The ionized portion could be $\phi_{i}=10^{-16} N_{D}$, which should be quite small.

\section{Escape Velocity of Polarized Molecules}

The effect the electric field may have on a polarized molecule can be determined as follows. The force on a polarized molecule in a nonuniform electric field is given by

$$
F_{e}=M \cdot \nabla \mathbf{E} \text {, }
$$

where $M=q d$ is the dipole moment of the molecule and $\nabla \mathbf{E}$ is the gradient of the field. The potential at a distance $r$ from a sphere of radius $a$ whose surface is at a potential $V_{0}$ is

$$
V=V_{0} a / r
$$

The field corresponding to this potential is

$$
\mathrm{E}=\frac{\Delta V}{\Delta r}=\frac{V_{0} a}{r^{2}}
$$

and its gradient is

$$
\nabla \mathbf{E}=\frac{\Delta E}{\Delta r}=\frac{2 V_{0} a}{r^{3}}
$$

Consequently, the maximum force exerted on the molecule is

$$
F=M \frac{2 V_{0} a}{r^{3}}
$$

which, for a water molecule $\left(M=6 \times 10^{-28} \mathrm{C}-\mathrm{cm}\right)$ located at $a=r=0.5 \mathrm{~m}$, and a spacecraft surface potential of $10 \mathrm{~V}$, will give a force

$$
\begin{aligned}
F_{e} & =\left(6 \times 10^{-28}\right) \frac{2 \times 10}{(50)^{2}}=4.8 \times 10^{-30} \mathrm{C}-\mathrm{V}-\mathrm{cm}^{-1} \\
& =4.8 \times 10^{-28} \mathrm{~N} .
\end{aligned}
$$

The escape velocity, equating kinetic to potential energy, for $m=3 \times 10^{-26} \mathrm{~kg}$ (the mass of an $\mathrm{H}_{2} \mathrm{O}$ molecule) is

$$
\begin{aligned}
v_{e} & =\left(\frac{2 F_{e} d}{m}\right)^{1 / 2}=\left(2 \times \frac{4.8 \times 10^{-28} \times 0.5}{3 \times 10^{-26}}\right)^{1 / 2} \\
& =1.26 \times 10^{-1} \mathrm{~m}-\mathrm{s}^{-1} .
\end{aligned}
$$

The actual velocity is less than this because the energy is used in part to rotate the molecule. However, comparing this value with the thermal velocity of water $\left(5.5 \times 10^{2} \mathrm{~m}-\mathrm{s}^{-1}\right.$ at $\left.273 \mathrm{~K}\right)$, one concludes that the molecule will be affected very little by the field and that calculations disregarding this 
effect are acceptable. It is interesting to note that observations aboard Pegasus II revealed slightly curved trajectories of contaminants with velocities of the order of $1 \mathrm{~m}-\mathrm{s}^{-1}$.* $^{*}$

*Grenda, R., Neste, S., and Soberman, R. K., "Contaminant Particle Trajectories Near a Spacecraft", Space Research IX, NorthHolland Publishing Co., Amsterdam, 1969. 
OFFICIAL BUSINESS

PENALTY FOR PRIVATE USE \$300
FIRST CLASS MAIL.
POSTAGE AND FEES PAID NATIONAL AERONAUTICS AND SPACE ADMINISTRATION

003001 C1 U 31720512 S00903DS

DEPT OF THE AIB PORCE

AF WEAPONS LAB (AFSC)

TECH LIBRARY/WLOL/

ATTN: E LOU BOWMAN, CHIEF

KIRTLAND AFB NM 87117

POSTMASTER: If Undeliverable (Section 158 Postal Manual) Do Not Return

"The aeronautical and space activities of the United States shall be conducted so as to contribute ... to the expansion of buman knowledge of phenomena in the atmosphere and space. The Administration shall provide for the widest practicable and appropriate dissemination of information concerning its activities and the results thereof."

- National Aeronautics and Space ACt of 1958

\section{NASA SCIENTIFIC AND TECHNICAL PUBLICATIONS}

TECHNICAL REPORTS: Scientific and technical information considered important, complete, and a lasting contribution to existing knowledge.

TECHNICAL NOTES: Information less broad in scope but nevertheless of importance as a contribution to existing knowledge.

TECHNICAL MEMORANDUMS:

Information receiving limited distribution because of preliminary data, security classification, or other reasons.

CONTRACTOR REPORTS: Scientific and technical information generated under a NASA contract or grant and considered an important contribution to existing knowledge.
TECHNICAL TRANSLATIONS: Information published in a foreign language considered to merit NASA distribution in English.

SPECIAL PUBLICATIONS: Information derived from or of value to NASA activities. Publications include conference proceedings, monographs, data compilations, handbooks, sourcebooks, and special bibliographies.

TECHNOLOGY UTILIZATION PUBLICATIONS: Information on technology used by NASA that may be of particular interest in commercial and other non-aerospace applications. Publications include Tech Briefs, Technology Utilization Reports and

Technology Surveys.

Details on the availability of these publications may be obtained from: 